\title{
Forces on Liquid Lithium Modules in a Tokamak Blanket Due to the Pulsed Poloidal Magnetic Field
}

\author{
J. S. Walker
}

W. M. Wells

\section{MASTER}




\section{DISCLAIMER}

This report was prepared as an account of work sponsored by an agency of the United States Government. Neither the United States Government nor any agency Thereof, nor any of their employees, makes any warranty, express or implied, or assumes any legal liability or responsibility for the accuracy, completeness, or usefulness of any information, apparatus, product, or process disclosed, or represents that its use would not infringe privately owned rights. Reference herein to any specific commercial product, process, or service by trade name, trademark, manufacturer, or otherwise does not necessarily constitute or imply its endorsement, recommendation, or favoring by the United States Government or any agency thereof. The views and opinions of authors expressed herein do not necessarily state or reflect those of the United States Government or any agency thereof. 


\section{DISCLAIMER}

Portions of this document may be illegible in electronic image products. Images are produced from the best available original document. 


\title{
Printed in the United States of America. Available from National Technical Information Service \\ U.S. Department of Commerce \\ 5285 Port Royal Road, Springfield, Virginia 22161 \\ Price: Printed Copy $\$ 5.25$; Microfiche $\$ 3.00$
}

\begin{abstract}
This report was prepared as an account of work sponsored by an agency of the United States Government. Neither the United States Government nor any agency thereof, nor any of their employees, contractors, subcontractors, or their employees, makes any warranty, express or implied, nor assumes any legal liability or responsibility for any third party's use or the results of such use of any information, apparatus, product or process disclosed in this report, nor represents that its use by such third party would not infringe privately owned rights.
\end{abstract}


ORNL / TM- 6907

Dist. Category UC-20 d

Contract No. W-7405-eng-26

FUSION ENERGY DIVISION

FORCES ON LIQUID LITHIUM MODULES IN A TOKAMAK

BLANKET DUE TO THE PULSED POLOIDAL MAGNETIC FIELD

J. S. Walker

University of Illinois, Urbana, IL 61801

W. M. Wel1s

Date Published: September 1979

This repon was propared os an arrount of ungth

sponsored by the United States Govemment. Neither the

United States nor the United States Department of

Energy, nor any of their employees, nor any of their

contractors, subcontractors, or their employees, makes

any warranty, express or implied, or assumes any lega!

liability or responsibility for the accuracy, completeness

or usefulness of any information, apparatus, product or

process disclosed, or represents that its use would not infringe privately owited tidello.

Prepared by the

OAK RIDGE NATIONAL LABORATORY

Oak Ridge, Tennessee 37830

operated by

UNION CARBIDE CORPORATION

for the

DEPARTMENT OF ENERGY 


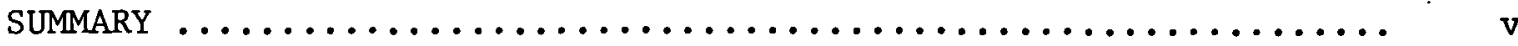

ABSTRACT $\ldots \ldots \ldots \ldots \ldots \ldots \ldots \ldots \ldots \ldots \ldots \ldots \ldots \ldots \ldots \ldots \ldots \ldots \ldots \ldots \ldots \ldots \ldots \ldots$

1. INTRODUCTION $\ldots \ldots \ldots \ldots \ldots \ldots \ldots \ldots \ldots \ldots \ldots \ldots \ldots \ldots \ldots \ldots \ldots \ldots \ldots \ldots$

2. GOVERNING EQUATIONS AND ASSUMPTIONS $\ldots \ldots \ldots \ldots \ldots \ldots \ldots \ldots \ldots$

3. TIME-DEPENDENT AXIAL MAGNETIC FIELD $\ldots \ldots \ldots \ldots \ldots \ldots \ldots \ldots \ldots$

4. TIME-DEPENDENT TRANSVERSE MAGNETIC FIELD .............. 17

5. NUMERICAL EXAMPLES FOR THE ORNL/WESTINGHOUSE

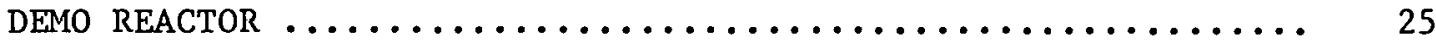

5.1 Values of $\dot{B}(t)$ for Poloidal Field and Values of the Dimensionless Parameters ...................... 25

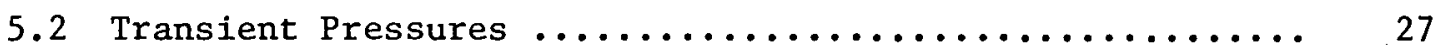

5.3 Various Stresses in the Wall ................... 27

5.4 Ring Bending Due to Nonuniform Pressure ............. 29

5.5 Significance of the Results and Scaling Considerations ............................ 31

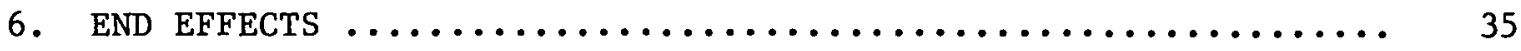

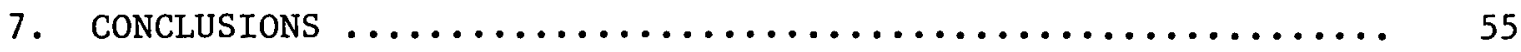

ACKNOWLEDGMENTS $\ldots \ldots \ldots \ldots \ldots \ldots \ldots \ldots \ldots \ldots \ldots \ldots \ldots \ldots \ldots \ldots \ldots$

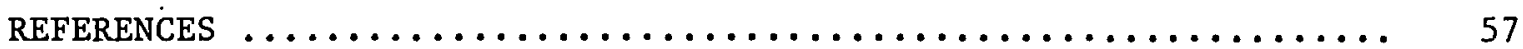




\section{PAGES iii to iv WERE INTENTIONALLY LEFT BLANK}




\section{SUMMARY}

For a fusion reactor blanket that contains molten lithium or lithium alloys, forces will arise when the magnetic field is changed, resulting in pressures and stresses. The writers are aware of two analyses that treated this problem, 1,2 but they treated the conductive metal as though it were a rigid solid. While the order of magnitude of gross forces on the rigid solids should be an upper limit to the real problem, such an analysis is less than satisfying because of an inability to treat important aspects of the problem (such as stresses in containment vessels arising from preooures in the conductive fluid).

In this paper derivation of pressures, forces, and stresses is made from the appropriately simplified governing equations (Maxwell's equations, Navier-Stokes equations, and Ohm's law) for two limiting cases. These derivations are for infinite length cylinders, and for both cases a component of the magnetic field that is assumed to be constant is normal to the cylinder axis (the toroidal field). The timevarying component of the field (the poloidal field) is assumed to be along the cylinder axis in one case and is normal to both the axis and the toroidal field in the other case.

Using the formulas derived in this manner, pertinent pressures and stresses are calculated for the case of the ORNL/Westinghouse Tokamak Blanket Study, ${ }^{3}$ where these limiting cases are approached; it is shown that the quantities are nearly negligible for this particular design concept. This desirable situation is a consequence of the fact that the minimum dimension of the blanket modules is small compared to the blanket thickness. This situation prevails for normal startup and shutdown rates of change of poloidal field and for all but the most severe plasma disruption that was assumed. It is further indicated that difficulties can be expected with stresses, which would result for blanket modules having minimum dimensions about equal to the blanket thickness. Finally, the consequences of end effects for finite length cylinders are discussed; it is expected that the end effects are secondary in effect. 
Perhaps the primary value of this report lies not so much in the specific analytical results, but rather in the illustration that such treatment can be applied to a broad range of blanket configurations containing liquid lithium, thus filling a long standing need. 
This paper treats cylindrical modules filled with liquid lithium in the presence of a steady toroidal magnetic field and a time-dependent poloidal field. Solutions for liquid lithium flows and formulas for the forces on the modules are presented for both axial and transverse poloidal fields. Numerical examples are presented for the design in the ORNL/Westinghouse Tokamak Blanket Study. The initial analysis ignores the ends of the modules and treats infinitely long pipes, but the effects of the ends are also treated. Calculations and conclusions based on the solutions for infinitely long pipes are not significantly altered by end effects. 


\section{INTRODUCTION}

In a power plant version of a fusion reactor that utilizes the deuterium-tritium (D-T) fusion reaction, it will be necessary for lithium to be present to produce the tritium consumed in the fusion reaction. This can be done by means of the nuclear reactions that occur when neutrons interact with the two lithium isotopes. Probably the most common chemical form of lithium studied for this purpose is the elemental form, which is usually in the liquid state.

The first line of development leading toward a power producing reactor in the U.S. fusion energy program is the toroidal-shaped tokamak configuration. It was generally believed that a tokamak must be operated in a pulsed mode where the power-on portion of the cycle is typically a few minutes and the power-off portion is of the order of one-tenth the duration of the power-on portion. The particular concept dealt with for example calculations presented in Sect. 5 is that in the ORNL/ Westinghouse Tokamak Blanket Study. ${ }^{3}$ The arrangement of lithium containment seen in Fig. 1 consists of a large number of cylinders. Figure 2 is a cross section of one of these cylinders, and it may be seen that the helium coolant circulates in an annular region near the outside of the cylinder. The magnetic field consists of a toroidal component that is constant with time and a poloidal component that is constant in time during the power-on period with a magnitude of $210 \%$ of the toroidal field strength, but the poloidal component is off during the power-off period. The poloidal field results from plasma current, current in equilibrium field coils, and current in ohmic heating coils. Thus, the toroidal field is in or out of the paper in Fig. 1, and the poloidal field vector is approximately tangent to the plasma boundary in

Fig. 1. It is this pulsing of the poloidal field that can cause the types of forces dealt with herein. This pulsing can arise from deliberate control action or from the so-called disruption (see Ref. 4) wherein the plasma substantially ceases to exist in a very short time with similar consequences for the plasma current.

To begin, the ends of the cylinder shown in Fig. 2 are ignored, and its configuration is modeled by an infinitely long, circular pipe that 


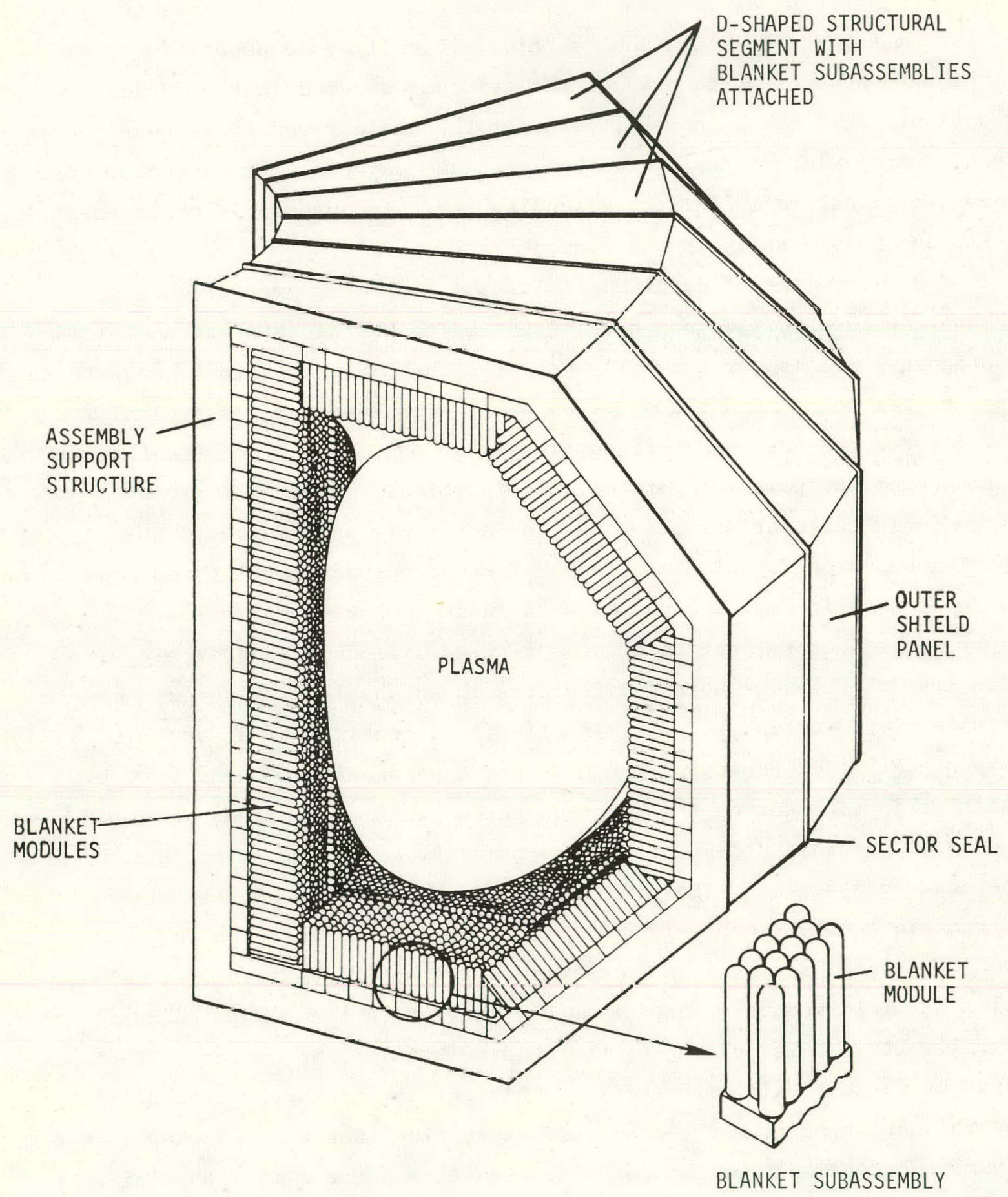

Fig. 1. Cross section of a toroidal reactor showing the proposed arrangement of liquid lithium modules. Poloidal magnetic field lines are nearly tangent to the plasma in the blanket region. 


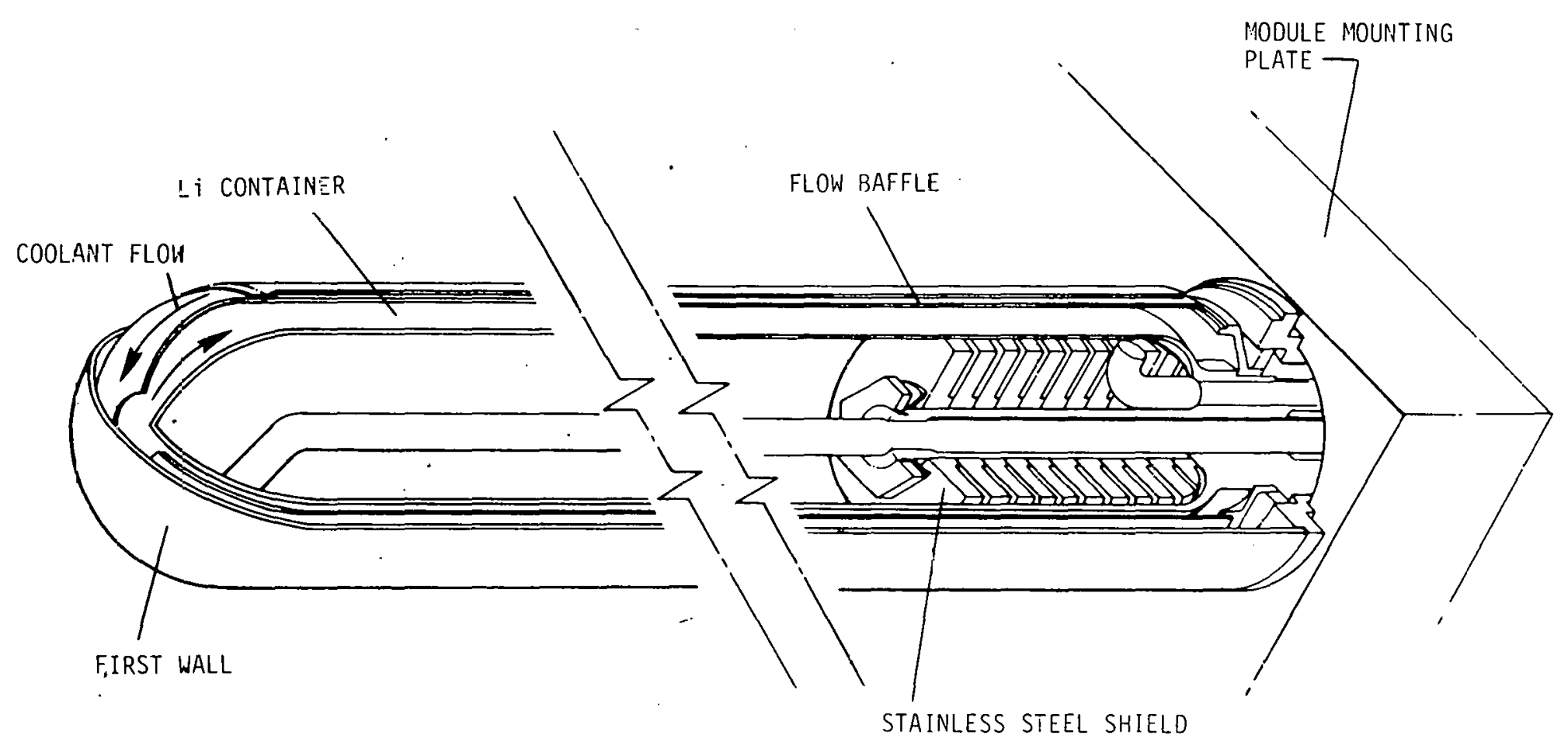

Fig. 2. Cylindrical blanket module. 
has a thin, electrically conducting wall filled with a liquid metal that is at rest when the magnetic field is steady. From Fig. 1, it is evident that the poloidal field is transverse to some cylinders and has both transverse and axial components relative to the other cylinders. As discussed in Sect. 7, the forces due to the transverse and axial components of the poloidal field can be treated separately. An analysis for a time-dependent axial magnetic field is presented in Sect. 3, and an analysis for a time-dependent transverse field is presented in Sect. 4. Example calculations based on these analyses are presented in Sect. 5. Section 6 presents a partial analysis of end effects, i.e., the corrections because the actual cylinders are not infinitely long. 


\section{GOVERNING EQUATIONS AND ASSUMPTIONS}

The liquid metal is contained in an infinitely long, circular pipe with an inside radius, a, a wall thickness, $T$, and an electrical conductivity for the wall material, $\sigma_{\mathrm{w}}$ (see Fig. 3). The cencerline of the pipe coincides with the $z$ axis, and a constant, uniform magnetic field with the strength $B_{y}$ is applied in the $y$ direction. An additional time-dependent, uniform magnetic field is applied either in the $z$ direction with the strength $B_{z}(t)$ (treated in Sect. 3 ), or in the $x$ direction with the strength $B_{x}(t)$ (treated in sect. 4).

The following are dimensionless equations governing the liquid metal flow with constant physical properties in the presence of a magnetic field:

$$
\begin{aligned}
& N^{-1}[\underset{m}{\partial v} / \partial t+(\underset{m}{v} \cdot \underset{m}{\nabla}) \underset{m}{v}]=-\underset{m}{\nabla} p+\underset{m}{j} \times \underset{m}{B}+M^{-2} \nabla^{2} \underset{m}{v} \\
& \underset{m}{\nabla} \cdot \underset{m}{v}=0, \underset{m}{\nabla} \cdot \underset{m}{j}=0, \quad \underset{m}{\nabla} \cdot \underset{m}{B}=0, \underset{m}{j}=\underset{m}{E}+\underset{m}{v} \times \underset{m}{B},(I b, c, d, e) \\
& \underset{m}{\nabla} \times \underset{m}{B}=R_{m_{m}}^{j}, \quad \underset{m}{\nabla} \times \underset{m}{E}=-\underset{m}{\partial B} / \partial t,
\end{aligned}
$$

where displacement currents are neglected in Eq. (1f), as usual in nonrelativistic magnetohydrodynamics (see Ref. 5, Chapter 1). Here, v, $p, \underset{m}{j}, \underset{m}{B}$, and $\underset{m}{E}$ are the fluid velocity, pressure, electric current density, magnetic field, and electric field, respectively, and

$$
\mathrm{N}=\mathrm{B}_{\mathrm{y}}^{2} \sigma \tau / \rho, \quad \mathrm{M}=\mathrm{B}_{\mathrm{y}} \mathrm{a}(\sigma / \mathrm{n})^{1 / 2}, \quad \mathrm{R}_{\mathrm{m}}=\mu \sigma \mathrm{a}^{2} / \tau
$$

are the inceraction parameter, Hartmann number, and magnetic Reynolds number, respectively. The fluid's electrical conductivity, density, viscosity, and magnetic permeability are denoted by $\sigma, \rho, \eta$, and $\mu$, respectively, while the characteristic time, $\tau$, is taken as the length of time required for the poloidal field strength to change from zero to its maximum value or vice versa. We have chosen the quantities $a / \tau$, $\mathrm{aB}_{\mathrm{y}} / \tau, \sigma a \mathrm{~B}_{\mathrm{y}} / \tau$, and $\sigma \mathrm{a}^{2} \mathrm{~B}_{\mathrm{y}}^{2} / \tau$ as the characteristic velocity, electric field, 


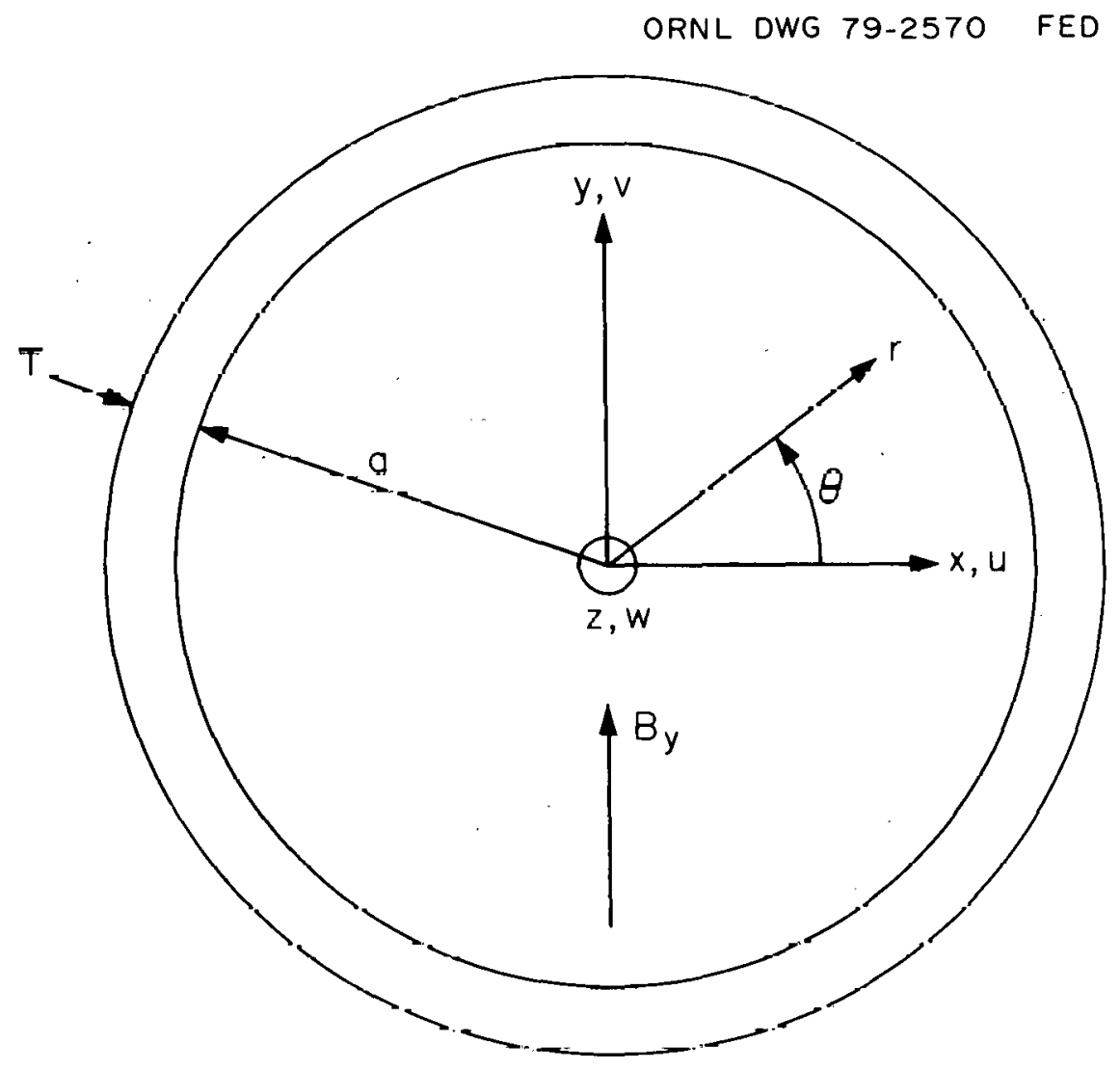

Fig. 3. Cross section of pipe showing coordinates, components of velocity, and the constant (toroidal) component of the magnetic field, $B_{y}$. 
electric current density, and pressure, respectively. The dimensionless inside radius of the pipe is one, and the dimensionless y component of the applied magnetic field is also one.

The first assumption is that $R_{m} \ll 1$, so that the right-hand side of Eq. (lf) is negligible, and Eqs. (ld,f) indicate that the magnetic field is equal everywhere to the uniform, applied magnetic field. The second assumption is that $N \gg 1$, so that the inertial terms on the left-hand side of Eq. (1a) are negligible. The third assumption is that $M \gg 1$, so that the interior of the pipe may be subdivided into a core region, in which the final, viscous term in Eq. (1a) is negligible, and a Hartmann layer region of $O\left(M^{-1}\right)$ thickness adjacent to the pipe wall. The fourth assumption is that all variables, except pressure, are independent of $z$. The partial derivative of Eq. (1a) with respect to $z$ gives $\nabla(\partial p / \partial z)=0$, so that $\partial p / \partial z=P(t)$. The remaining equations are Eq. (1a), with zero on the left-hand side, and Eqs. (1b,c,e,g).

The boundary condition on the velocity is

$$
\underset{m}{v}=0, \text { at } \quad r=1 \text {. }
$$

The velocity in the Hartmann layer satisfies this boundary condition and matches the velocity in the core, as long as the core velocity satisfies

$$
v_{r}=0, \text { at } \quad r=1 \text {, }
$$

neglecting $O\left(\mathrm{M}^{-1}\right)$ terms (see Ref. 5, Chapter 6). The tangential electric field $\left(E_{\theta}, E_{z}\right)$ and normal electric current $\left(j_{r}\right)$ are continuous across the Hartmann layer, again neglecting $\mathrm{O}\left(\mathrm{M}^{-1}\right)$ terms. The boundary condition on the electric current depends on the conductance ratio,

$$
\varepsilon=\sigma_{\mathrm{w}} \mathrm{T} / \sigma_{\mathrm{a}}
$$

and it is treated separately for each of the two cases considered in the next two sections. 


\section{THIS PAGE}

WAS INTENTIONALLY

LEFT BLANK 


\section{TIME-DEPENDENT AXIAL MAGNETIC FIELD}

For the case considered in this section, the dimensionless magnetic field is given by $\underset{m}{B}=\hat{y}+f(t) \underset{m}{\hat{z}}$, where $f=B_{z}(t) / B_{y}$, and $\underset{m}{\hat{y}}$ and $\underset{m}{\hat{z}}$ are unit vectors. The boundary value problem [Eqs. $(1,2)]$ separates into two decoupled problems: one governing $u, v, j_{z}, E_{z}$ and the other governing $w, P, j_{x}, j_{y}, E_{x}, E_{y}$.

The $\mathrm{x}$ and $\mathrm{y}$ components of $\mathrm{Eq}$. ( $1 \mathrm{~g}$ ) indicate that $\mathrm{E}_{\mathrm{z}}$ is a function of $t$ only. Equation (lb) indicates that a streamfunction, $\psi(x, y, t)$, can be introduced such that

$$
\mathbf{u}=-\partial \psi / \partial \mathrm{y}, \quad \mathrm{v}=\partial \psi / \partial \mathbf{x}
$$

The $z$ component of $\mathrm{Eq} .(\mathrm{le})$ is now

$$
j_{z}=E_{z}(t)-\partial \psi / \partial y,
$$

and this equation, together with the $z$ component of the curl of Eqs. (1a) and (1c), gives

$$
M^{-2} \nabla^{4} \psi=\partial^{2} \psi / \partial y^{2}
$$

The boundary conditions [Eq. (2)] become

$$
\psi=\partial \psi / \partial r=0, \text { at } \quad r=1
$$

The solution of this homogeneous, elliptic problem is $\psi=0$. If there is no voltage drop applied along the pipe, then none is induced by the time-dependent axial magnetic field, and

$$
u=v=j_{z}=E_{z}=0
$$

In the core region, the final viscous term in Eq. (la) is negligible, and this equation becomes 


$$
\partial p / \partial x=f j_{y}, \quad \partial p / \partial y=-f j_{x}, \quad j_{x}=P(t) . \quad(4 a, b, c)
$$

Equations $(1 c, e)$ now give

$$
j_{y}=E_{y}(x, t), \quad E_{x}=w+P(t),
$$

and Eq. (1g) is

$$
\partial E_{x} / \partial y-\partial E_{y} / \partial x=\dot{f}(t)
$$

where the dot denotes differentiation with respect to $t$. The hnundary condition [Eq. (3)] is already satisfied, and we need the boundary condition on the electric current in order to go any further.

The equations governing the dimensional electrical variables in the pipe wall are

$$
\underset{m}{\nabla} \cdot \underset{m}{j}=0, \quad \underset{m}{j}=\sigma_{w m}^{E}, \quad \underset{m}{\nabla} \times \underset{m}{E}=-\underset{m}{B} / \partial t
$$

The $r$ and $\theta$ components of Eq. (5c) indicate that $E_{z}$ is independent of $r$ and $\theta$, and $\mathrm{E}_{z}$ in the wall must equal $\mathrm{E}_{z}$ in the fluid at $r=a$. Theretore, $j_{z}=E_{z}=0$ in the wall. Equations $(5 a, b)$ indicate that a current streamfunction $\Psi(r, \theta, t)$ can be introduced, such that

$$
j_{r} / \sigma_{w}=F_{r}=r^{-1} \partial \Psi / \partial A, \quad j_{0} / \sigma_{w} \equiv E_{\theta}=-\partial \Psi / \partial r
$$

The $z$ component of Eq. (5c) becomes

$$
\partial^{2} \Psi / \partial r^{2}+r^{-1} \partial \Psi / \partial r+r^{-2} \partial^{2} \Psi / \partial \theta^{2}=\dot{B}_{z}(t)
$$

If the pipe is surrounded by an electrically insulating medium, then

$$
\mathrm{j}_{\mathrm{r}}=\Psi=0 \text {, at } \mathrm{r}=\mathrm{a}+\mathrm{T} \text {, }
$$


and continuity of the tangential electric field at the fluid-wall interface gives

$$
\partial \Psi / \partial r=-E_{\theta}^{*}(\theta, t), \text { at } r=a,
$$

where $\mathrm{E}_{\theta}^{*}$ is the dimensional, azimuthal electric field in the fluid, evaluated at $\mathrm{r}=\mathrm{a}$.

If $\mathrm{T} \ll \mathrm{a}$, then the first term on the left-hand side of $\mathrm{Eq}$. (6) is much larger than the other two terms here, which are neglected. The solution of the simplified Eq. (6), which satisfies Eqs. (7a,b), is

$$
\Psi=(a+T-r) E_{\theta}^{*}+\left[(r-a)^{2}-T^{2}\right] B_{z}(t) / 2
$$

The radial electric current must be continuous at the wall-fluid interface, so that the dimensional electrical variables in the fluid must satisfy the boundary condition,

$$
\mathrm{j}_{\mathrm{r}}=\sigma_{\mathrm{w}} \mathrm{Ta}^{-1} \partial \mathrm{E}_{\theta} / \partial \theta \text {, at } \mathrm{r}=\mathrm{a} \text {, }
$$

or, in terms of dimensionless fluid variables,

$$
j_{r}=\varepsilon \partial E_{\theta} / \partial \theta, \text { at } \quad r=1 \text {. }
$$

Because the change in normal (radial) electric current across the Hartmann layer is $O\left(M^{-1}\right)$, Eq. (9) can be applied to the core solution if $\varepsilon \gg \mathrm{M}^{-1}$. It is compatible with the assumption that $\mathrm{T} \ll \mathrm{a}$ in order to assume that $\varepsilon \ll 1$. Indeed, the thin, conducting wall assumptions $\left(\mathrm{T} / \mathrm{a} \ll 1\right.$, and $\mathrm{M}^{-1} \ll \varepsilon \ll 1$ ) are appropriate for liquid 1ithium flows in fusion reactors (see Ref. 6). Ihe core variables are written as asymptotic expansions for small $\varepsilon$, such as

$$
w=w_{0}+\varepsilon w_{1}+o\left(\varepsilon^{2}, M^{-1}\right)
$$


and Eqs. (4) become two equations: one has zero and the other has one added as subscripts to all variables except $f$, with the second of Eqs. (4f) equal to zero, rather than $\dot{\mathrm{f}}$.

The boundary condition [Eq.(9)] gives $j_{r_{0}}=0$, at $r=1$, or, in terms of cartesian coordinates,

$$
x j_{x_{0}} \pm\left(1-x^{2}\right)^{1 / 2} j_{y_{0}}=0, \quad \text { at } \quad y= \pm\left(1-x^{2}\right)^{1 / 2}
$$

Introducing Eqs. (4c,d), with zero subscripts, leads to the results

$$
j_{x_{0}}=j_{y_{0}}=E_{y_{0}}=P_{0}=0 \text {. }
$$

Equations $(4 a, b, e, f)$ then give

$$
p_{0}=p_{0}(t), \quad w_{0}=E_{x_{0}}=y \dot{f}(t)+g(x, t) .
$$

The zeroth-order, azimuthal electric field, evaluated at $r=1$, is then

$$
H_{\dot{\theta}_{n}}=-\sin ^{2} \dot{\theta} \dot{\mathrm{I}}(t)-\sin \dot{\theta} \dot{g}(\cos \dot{\theta}, t) .
$$

Taking the derivative of this with respect to $\theta$, introducing the result into Eq. (9), and expressing the result in cartesian coordinates lead to the boundary condition

$$
\begin{aligned}
x j_{x_{1}} \pm\left(1-x^{2}\right)^{1 / 2} j_{y_{l}}= & \pm 2 x\left(1-x^{2}\right)^{1 / 2} \dot{f}(t)-x g(x, t) \\
& +\left(1-x^{2}\right) \partial g / \partial x(x, t), \text { at } y= \pm\left(1-x^{2}\right)^{1 / 2} .
\end{aligned}
$$

Introducing Eqs. $(4 c, d)$, with subscripts one, we obtain an equation for $j_{y_{1}}$, 


$$
j_{y_{1}}=-2 x \dot{f}(t)
$$

and a differential equation governing the integration function, $g$, which can be integrated to get

$$
g=G(t)\left(1-x^{2}\right)^{-1 / 2}-P_{1}(t)
$$

The first term on the right-hand side of the equation gives infinite velocities at $x= \pm 1$, and the Hartmann layer here cannot match such velocities (see Ref. 7 ); so $G(t)=0$. The uniform velocity, $w_{0}=-P_{I}(t)$, is the well-known, fully developed, flow solution (e.g., see Ref. 8) and is completely decoupled from the flow induced by the time-dependent magnetic field. Because we are interested in the latter, we set $P_{1}=0$, with no loss of generality. Therefore, $j_{x_{1}}=0, w_{0}=E_{x_{0}}=y \dot{f}(t)$, and $\mathrm{p}_{1}$ is given, to within a function of time, by Eqs. (4a,b). In a specific application, the condition that would determine this function of time would depend on how the cylinder is connected to external containers of lithium. We will assume that the average pressure is constant, which would be true for cylinders connected to large reservoirs of lithium at a constant pressure.

The results can be translated into dimensional quantities using the characteristic quantities given in the previous section. The nonzero dimensional core variables are

$$
\begin{aligned}
B_{y} w=E_{x}=y \dot{B}_{z}(t), \quad \sigma E_{y}=j_{y} & =-2 \sigma_{w} T a^{-1} \dot{B}_{z}(t), \\
p & =p_{o}+\left(\sigma_{w} T / 4 a\right)\left(a^{2}-4 x^{2}\right) B_{z}(t) \dot{B}_{z}(t) .
\end{aligned}
$$

In the Hartmann layer, w must match the core velocity, and it must satisfy the boundary condition [Eq. (2)]. The structure of Hartmann layers is well known (see Ref. 5, Chapter 6), and the dimensional velocity in the Hartmann layer is given by 
$\mathrm{w}=\mathrm{a} \sin \theta \mathrm{B}_{\mathrm{y}}^{-1} \dot{\mathrm{B}}_{\mathrm{z}}(\mathrm{t})\{1-\exp [-\mathrm{M}|\sin \theta|(\mathrm{a}-\mathrm{r}) / \mathrm{a}]\}$

The dimensional electric current in the wall is obtained from $\Psi$, given by $\mathrm{Eq}^{-}$(8), with $\mathrm{E}_{\hat{\theta}}^{*}=-\mathrm{a} \sin ^{2} \theta \dot{\mathrm{B}}_{z}(\mathrm{t})$;

$$
j_{r}=-\sigma_{w} \dot{B}_{z}(t) a\left(a r^{-1}-1\right) \sin 2 \theta, \quad j_{\theta}=-\sigma_{w} \dot{B}_{z}(t)\left(r-a \cos ^{2} \theta\right) .
$$

The forces on the pipe are the hydrodynamic force on the inside surface of the pipe and the electromagnetic body force in the pipe wall. The hydrodynamic force per unit area of the inside pipe surface consists of a radial component due to the difference between the local pressure and the constant, average pressure,

$$
h_{r}=p(r=a)-p_{0}=\sigma_{w} T a\left(\frac{1}{4}-\cos ^{2} \theta\right) B_{z}(t) \dot{B}_{z}(t),
$$

and an axial component due to the viscous shear in the Hartmann layer,

$$
h_{z}=A(n n)^{1 / 2} \sin A|\sin A| \dot{R}_{z}(t)
$$

'lihe body torce per unit volume, $\underset{m}{j} \times \underset{m}{b}$, can be integraced from $r=a$ to $r=a+T$ in order to obtain a body force per unit area of the pipe surface, $b$, where

$$
\begin{aligned}
& b_{F}=-\sigma_{w} T a \sin ^{2} \theta B_{z}(t) \dot{B}_{z}(t), \\
& b_{0}=\frac{1}{2} \sigma_{w} T^{2} \sin 2 \theta B_{z}(t) \dot{B}_{z}(t), \\
& b_{z}=\sigma_{w} T a \sin ^{3} \theta B_{y} \dot{B}_{z}(t),
\end{aligned}
$$

and where any term, which is $O(T / a)$ times that given in each expression here, has been dropped. 
The axial forces produce bending moments that act about axes parallel to the $\mathrm{x}$ axis and that are uniformly distributed along the pipe length. These distributed bending moments are

$$
\begin{aligned}
& m_{x}^{h}=(8 / 3) a^{3}(\sigma n)^{1 / 2} \dot{B}_{z}(t), \\
& m_{x}^{b}=(3 / 4) \pi a^{3} T \sigma_{w} B_{y} \dot{B}_{z}(t),
\end{aligned}
$$

where $\mathrm{m}_{\mathrm{x}}^{\mathrm{h}}$ and $\mathrm{m}_{\mathrm{x}}^{\mathrm{b}}$ are the distributed bending moments about axes parallel to the $x$ axis per unit $z$ length, due to $h_{z}$ and $b_{z}$, respectively. The ratio of these two is

$$
\mathrm{m}_{\mathrm{x}}^{\mathrm{h}} / \mathrm{m}_{\mathrm{x}}^{\mathrm{b}}=(32 / 9 \pi) \varepsilon^{-1} \mathrm{M}^{-1} \ll 1
$$

because $\varepsilon \gg M^{-1}$; so $m_{x}^{h} \ll m_{x}^{b}$.

Although both radial forces vary with $\theta$, their sum,

$$
h_{r}+b_{r}=-(3 / 4) \sigma_{w} T_{z}(t) \dot{B}_{z}(t)
$$

is independent of $\theta$, so that the total radial force produces no deformation except a symmetric radial expansion or contraction. The change in the hoop stress in the pipe due to this total radial force is

$$
\Delta \sigma_{\theta}=-(3 / 4) a^{2} \sigma_{w z} B_{z}(t) \dot{B}_{z}(t)
$$

Because the initial hoop stress, $\sigma_{\theta}=a_{0} / T$, is positive, the hoop stress is reduced when the magnitude of the axial magnetic field is increasing, but the hoop stress is increased when the magnitude of the axial magnetic field is decreasing.

The azimuthal force $b_{\theta}$ is the only force that tends to deform the circular cross section of the pipe. This azimuthal force tends to elongate the cross section in the $\mathrm{y}$ direction when the magnitude of $\mathrm{B}_{2}$ 
is increasing, and it tends to elongate the cross section in the $x$ direction when the magnitude of $\mathrm{B}_{z}$ is decreasing. Balancing the net force due to $b_{\theta}$ in the $y$ direction on the upper half of the pipe, or the net force in the $x$ direction on the right half of the pipe by increases in hoop stress, we find that the maximum changes in hoop stress in the pipe are

$$
\Delta \sigma_{\theta}^{\theta}= \pm \frac{1}{3} \sigma_{w} \mathrm{TaB}_{z}(t) \dot{\mathrm{B}}_{z}(t)
$$

The ratio of this change in hoop stress to the change due to the cotal radial force,

$$
\Delta \sigma_{\theta}^{\theta} / \Delta \sigma_{\theta}=4 \mathrm{~T} / 9 \mathrm{a} \ll 1
$$

so that hoop stresses and deformations due to $b_{\theta}$ can generally be neglected.

Typical values for pressures and stresses based on the formulas derived here are presented in Sect. 5. 


\section{TIME-DEPENDENT TRANSVERSE MAGNETIC FIELD}

For the case considered in this section, the dimensionless magnetic field is given by $\underset{m}{B}=f(t) \underset{m}{\hat{x}}+\underset{m}{\hat{y}}=F^{-1}(t) \underset{m}{\hat{Y}}$, where $f=B_{x}(t) / B_{y}$, and $F=\left(1+f^{2}\right)^{-1 / 2} ; \underset{m}{\hat{x}}, \hat{y}$, and $\underset{m}{\hat{y}}$ are unit vectors. The cartesian coordinates $(X, Y, z)$ rotate with time, so that the $Y$ axis is always parallel to $\mathrm{B}(t)$ (see Fig. 4). These coordinates are rotated about the minus $z$ axis by an angle, $\alpha=\operatorname{arc}$ tan $f$, relative to the fixed $(x, y, z)$ coordinates. Cylindrical coordinates are either $(r, \theta, z)$, with $\theta$ measured from the $x$ axis, or $(r, \beta, z)$, with $\beta$ measured from the $x$ axis, so that $\beta=\theta+\alpha$. In Eq. (la), with the left-hand side replaced by zero, and Eqs. (lb,c,e,g), there are no derivatives with respect to time, except in $\partial \mathrm{m} / \partial t=\dot{\mathrm{f}}(t) \hat{\mathrm{m}}$, which is a given driving function. Therefore, the solution at each instant is independent of that at other times, and the equations can be solved using instantaneous, non-Newtonian coordinates $(X, Y, z)$.

Once again, the boundary value problem separates into two decoupled problems: one governing $j_{x}, j_{y}, E_{x}, E_{y}, w, P$ and the other governing $j_{z}, E_{z}, u, v, p$. Equation (1c) indicates that a current streamfunction. $s(X, Y, t)$ can be introduced, such that

$$
{ }^{j} X=E_{X}-F^{-1} w=\partial s / \partial Y, \quad j_{Y}=E_{Y}=-\partial s / \partial X
$$

where Eq. (le) has also been used. The $z$ components of Eqs. (1a,g) now becume

$$
M^{-2} \nabla^{2} w+F^{-1} \partial s / \partial Y=P(t), \quad \nabla^{2} s+F^{-1} \partial w / \partial Y=0,
$$

respectively. These are the well-known equations governing fully developed flow along a pipe with an applied axial pressure gradient $P$. The solutions, which depend on the conductance ratio $\varepsilon$, are also well known (e.g., see Ref. 9). This pressure-driven, fully developed flow is completely decoupled from the flow induced by the time-dependent, transverse magnetic field, which is of interest here, so that, with no loss of generality, we can set 


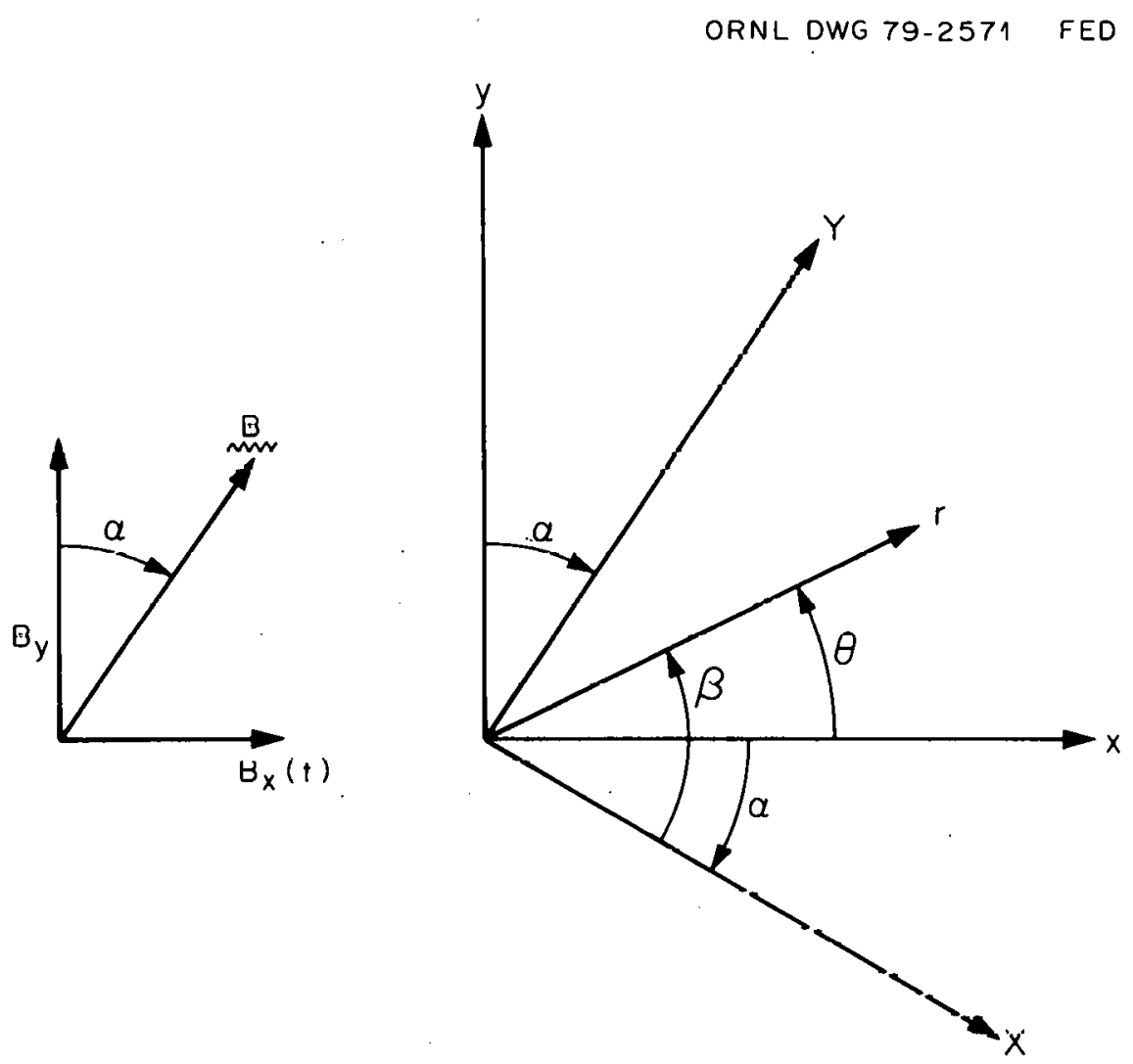

Fig. 4. Coordinate systems for time-dependent transverse magnetic field. 


$$
j_{x}=j_{y}=s=E_{x}=E_{y}=w=P=0 \text {. }
$$

In the core, the final viscous term in Eq. (1a) is negligible, so that the $\mathrm{Y}$ component of this equation indicates that $\mathrm{p}$ is independent of $Y$, and the $X$ component gives

$$
j_{z}=-F(t) \partial p / \partial X(X, t) \text {. }
$$

Equation (1b) indicates that a streamfunction, $\psi(x, y, t)$, can be introduced, such that

$$
\mathrm{v}=\partial \psi / \partial \mathrm{x}, \quad \mathrm{u}=-\partial \psi / \partial \mathrm{y},
$$

so that the boundary condition [Eq. (3)] becomes

$$
\psi=0, \quad \text { at } \quad y= \pm\left(1-x^{2}\right)^{1 / 2} \quad \text { or } \quad Y= \pm\left(1-x^{2}\right)^{1 / 2}
$$

The $y$ component of $\mathrm{Eq} \cdot(1 \mathrm{~g})$ indicates that $\mathrm{E}_{z}$ is independent of $x$, and the $x$ component can be integrated to cbtain

$$
E_{z}=-y \dot{f}(t)+E_{0}(t)=F(f X-Y) \dot{f}+E_{0}(t) .
$$

When the results for $\mathrm{j}_{z}$ and $\mathrm{E}_{7}$ are introduced into the $z$ component of Eq. (le), we obtain ar equation for $\partial \psi / \partial Y$, which can be integrated, with respect to $Y$, to obtain

$$
\psi=\mathrm{YF}^{2} \partial \mathrm{P} / \partial \mathrm{X}(\mathrm{X}, \mathrm{t})+\mathrm{F}^{2} \dot{\mathrm{f}}\left(\mathrm{XXY}-\mathrm{Y}^{2} / 2\right)+\mathrm{YFE} \mathrm{O}_{\mathrm{O}}(\mathrm{t})+\mathrm{G}(\mathrm{X}, \mathrm{t})
$$

The boundary condition [Eq. (13)] now determines the pressure gradient and the integration function $G$, 


$$
\begin{aligned}
& \partial \mathrm{p} / \partial \mathrm{X}=-\dot{\mathrm{f}} \mathrm{fX}-\mathrm{F}^{-1} \mathrm{E}_{\mathrm{o}}(t), \\
& G=\dot{\mathrm{f}} \mathrm{F}^{2}\left(1-\mathrm{X}^{2}\right) / 2 .
\end{aligned}
$$

The quantity $\mathrm{E}_{\mathrm{o}}$ represents a uniform, applied, axial electric field, which drives a uniform, axial electric current in both the fluid and the wall. This electric field and current are completely decoupled from the problem of interest here; so $\mathrm{E}_{\mathrm{o}}$ can be set equal to zero with no loss of generallty. Equation (15a) can be intcgrated with respect to $x$, and the integration tunction of $t$ is once agalin delermined by the assumption that the average pressure is constant, so thar

$$
p=p_{0}+\dot{f}(t) f(t)\left(1-4 x^{2}\right) / 8
$$

When the results [Eq. (15)] are introduced into the expression [Eq. (14)], we obtain

$$
\psi=\dot{f}(t) F^{2}(t)\left(1-X^{2}-Y^{2}\right) / 2
$$

Because $\mathrm{r}^{2}=\mathrm{x}^{2}+\mathrm{y}^{2}=\mathrm{x}^{2}+\mathrm{y}^{2}$, the velocity is

$$
\mathrm{u}=\dot{\mathrm{f}}(\mathrm{t}) \mathrm{F}^{2}(\mathrm{t}) \mathrm{y}, \quad \mathrm{v}=-\dot{\mathrm{f}}(\mathrm{t}) \mathrm{F}^{2}(\mathrm{t}) \mathrm{x},
$$

or, in cylindrical coordinates,

$$
v_{r}=0, \quad v_{\theta}=-\dot{f}(t) F^{2}(t) r
$$

This motion is simply a rigid-body rotation about the $z$ axis.

The core solution has been determined without any boundary condition on the electric current or electric field in the fluid, evaluated at $r=1$. Therefore, this solution applies to flows in pipes with any thickness and any electrical conductivity. 
The results can be translated into dimensional results using the characteristic quantities given in Sect. 2. The nonzero, dimensional core variables are

$$
\begin{aligned}
& u=y B^{-2} B_{y} \dot{B}_{x}(t), \quad v=-x B^{-2} B_{y} \dot{B}_{x}(t), \\
& v_{\theta}=-r B^{-2} B_{y} \dot{B}_{x}(t), \quad E_{z}=-y \dot{B}_{x}(t), \\
& j_{z}=X \sigma B^{-1} B_{x}(t) \dot{B}_{x}(t), \quad p=p_{0}+\sigma B_{x}(t) \dot{B}_{x}(t)\left(a^{2}-4 X^{2}\right) / 8,
\end{aligned}
$$

where

$$
B(t)=\left[B_{x}^{2}(t)+B_{y}^{2}\right]^{1 / 2}, \quad X=B^{-1}\left[B_{y} x-B_{x}(t) y\right] .
$$

The velocity in the Hartmann layer is

$$
v_{\theta}=-a B^{-2} B_{y} \dot{B}_{x}(t)\left\{1-\exp \left[-B(\sigma / n)^{1 / 2}|\sin B|(a-r)\right]\right\} .
$$

The dimensional electrical variables in the pipe wall are once again governed by Eqs. (5). The $z$ component of Eq. (5c) indicates that a potential function $\phi(x, \theta, t)$ can be introduced, such that

$$
E_{r}=j_{r} / \sigma_{w}=-\partial \phi / \partial r, \quad E_{\theta}=j_{\theta} / \sigma_{w}=-r^{-1} \partial \phi / \partial \theta
$$

Equation (5a) indicates that $\phi$ satisfies Laplace's equation for $a \leqslant r \leqslant a+T$, the boundary condition for an insulating medium around the pipe becomes $\partial \phi / \partial r=0$, at $r=a+T$, and the continuity of. $F_{\theta}$ at the fluid-wall interface becomes $\phi=0$ at $r=a$. The solution to this problem is

$$
\phi=j_{r}=j_{\theta}=E_{r}=E_{\theta}=0
$$


The $y$ component of $\mathrm{Eq}$. (5c) indicates that $\mathrm{E}_{z}$ is independent of $\mathrm{x}$, and the $\mathrm{x}$ component can be integrated to determine $\mathrm{E}_{z}$ to within an integration function of $t$, which is determined by the continuity of $E_{z}$ at the fluid-wall interface; the result is

$$
j_{z} / \sigma_{w}=E_{z}=-y \dot{B}_{x}(t)=-r \sin \theta \dot{B}_{x}(t) .
$$

Again, no assumptions about $\mathrm{T}$ or $\sigma_{\mathrm{w}}$ have been made.

The electromagnetic body force per unit volume in the wall is

$$
\underset{m}{j} x \underset{m}{B}=r \text { oin } \dot{\theta} \sigma_{w} B(t) \dot{B}_{x}(t) \underset{m}{\hat{Y}} \text {, }
$$

where

$$
\hat{\mathrm{X}}=\cos \beta \underset{m}{\hat{r}}-\sin \beta \hat{\theta}_{m}^{\hat{\hat{r}}}, \quad \beta=\theta+\alpha, \quad \alpha=\operatorname{arc} \tan \left[\mathrm{B}_{\mathrm{x}}(\mathrm{t}) / \mathrm{B}_{\mathrm{y}}\right] .
$$

The $\theta$ component of this body force produces a torque on the pipe, which acts about the $z$ axis and which is uniformly distributed along the pipe. Integration with respect to $r$ and $\theta$ yields

$$
m_{z}^{b}=-\pi T \sigma_{w} B_{y} \dot{B}_{x}(t)\left(4 a^{3}+6 a^{2} T+4 a T^{2}+T^{3}\right) / 4,
$$

where $\mathrm{m}_{\mathrm{z}}^{\mathrm{b}}$ is the torque about the $\mathrm{z}$ axis per unit $\mathrm{z}$ length due to the electromagnetic body force in the pipe wall.

The body force [Eq. (17)] is in the plus X direction for $0<\theta<\pi$ and in the opposite direction for $-\pi<\theta<0$, so that it shears the cross section away from a circular shape. This deformation involves shear forces and bending moments in the pipe wall, as well as hoop stresses. An analysis of this defurmaliun is presented in the next section. Here, estimates of the shear stresses and hoop stress changes are presented for a thin wall, i.e., for $T \ll a$. First, the total body force in the $X$ direction per unit $z$ length on the $Y>0$ half of the pipc is equated to $2 \mathrm{T \tau} \theta \mathrm{r}$ to obtain an estimate for the shear stress in the pipe wall at $\beta=0$ and $\pi$, namely, 


$$
\tau_{r \theta}=a^{2} \sigma_{w} B_{y} \dot{B}_{x}(t)
$$

Second, the total body force in $x$ direction per unit $z$ length on the $\mathrm{X}>0$ half of the pipe is equated to $2 \mathrm{~T} \Delta \sigma_{\theta}^{b}$ to obtain an estimate for the change in hoop stress in the pipe, due to the body force, at $\beta= \pm \pi / 2$, namely,

$$
\Delta \sigma_{\theta}^{b}=-a^{2} \sigma_{w} B_{x}(t) \dot{B}_{x}(t)
$$

We note here that the changes in hoop stress at $\beta= \pm \pi / 2$ are not equal, because the loading is not symmetric. Equation (20) represents the average of changes in hoop stress at $\beta= \pm \pi / 2$.

In addition to the body force [Eq. (17)] in the pipe wall, there is a hydrodynamic force per unit area on the inside surface of the pipe. This force has a radial component due to the difference between the local pressure and the constant, average pressure,

$$
h_{r}=a^{2} \sigma B_{x}(t) \dot{B}_{x}(t)\left(1-4 \cos ^{2} \beta\right) / 8,
$$

and an azimuthal component due to the viscous shear force in the Hartmann layer,

$$
h_{\theta}=-(\sigma i i)^{l / 2} \mathrm{AB}^{-1} \mathrm{~B}_{\mathrm{y}} \dot{\mathrm{B}}_{\mathrm{x}}(\tau)|\sin \mathrm{B}|
$$

The azimuthal component produces a torque on the pipe, which acts about the $z$ axis and which is uniformly distributed along the pipe. Integration with respect to $\theta$ gives

$$
m_{z}^{h}=-4(\sigma n)^{1 / 2} a^{3} B^{-1} B_{y} \dot{B}_{x}(t)
$$


for the torque on the pipe about the $z$ axis, per unit $z$ length, due to the fluid viscous shear force. For $T \ll a$, the ratio of the torques

$$
\mathrm{m}_{\mathrm{z}}^{\mathrm{h}} / \mathrm{m}_{\mathrm{z}}^{\mathrm{b}}=(4 / \pi) \cos \alpha \varepsilon^{-1} \mathrm{M}^{-1} \ll 1 \text {, }
$$

as long as $\varepsilon \gg \mathrm{M}^{-1}$. i.

The radial hydrodynamic force, $h_{r}$, tends to elongate the cross section in the $Y$ direction, when the magnitude of $B_{X}$ is increasing, and in the $\mathrm{X}$ direction, when the magnitude of $\mathrm{B}_{\mathrm{X}}$ is decreasing. The maximum changes in hoop stress due to $h_{r}$ occur at $\beta= \pm \pi / 2$ and can be computed by equating the total force in the $X$ direction per unit $z$ length on the $X>0$ half of the pipe to $2 T \Delta \sigma_{\varepsilon}^{h}$, which gives

$$
\Delta \sigma_{\theta}^{h}=-(5 / 24) a^{3} T^{-1} \sigma B_{x}(t) \dot{B}_{x}(t)
$$

Because $h_{r}$ is symmetric about the $\mathrm{X}$ axis, the increases in hoop stress at $\beta= \pm \pi / 2$ are the same and are both given by this expression. The ratio of the estimate of the increases in hoop stress at the same points due to the body force in the pipe wall to the present increases is

$$
\Delta \sigma_{\theta}^{\mathrm{b}} / \Delta \sigma_{\theta}^{\mathrm{h}}=24 \varepsilon / 5
$$

Both the hydrodynamic and body forces tend to decrease the initially positive hoop stress, $\sigma_{\theta}=p_{0} a / T$, when the magnitude of $B_{x}$ is increaslug, and to increase $\sigma_{\theta}$, when the magnitude of $B_{x}$ is decreasing. 


\section{NUMERICAL EXAMPLES FOR THE ORNL/WESTINGHOUSE DEMO REACTOR}

The design configuration used for this evaluation is found in Ref. 3. The time variation of magnetic field is used in the ORNL TNS Program as discussed below. All calculations in this section are done using the formulas developed in Sects. 3 and 4 for infinite length cylinders. End effects are discussed in Sect. 6. The term "coaxial" as used below refers to the case where both toroidal and poloidal magnetic fields are normal to the cylinder axis (Sect. 4). In this case, the constant strength rotating field which approximates the resultant field is coaxial with the cylinder. The noncoaxial case referred to here is simply the other case treated in the derivation, i.e., the case where the poloidal field is along the axis of the cylinder (Sect. 3). In the Demo Reactor configuration, the noncoaxial case is only approached whereas the coaxial case is realized. The context here is one of doing a reasonable approximation with these new analytical tools; so rather than deal with the mixed cases, only the extreme cases (coaxial and noncoaxial) are considered.

\subsection{VALUES OF $\dot{B}(t)$ FOR POLOIDAL FIELD AND VALUES OF THE DIMENSIONLESS PARAMETERS}

For normal operation of the ORNL TNS (see Ref. 10), the rate of change of poloidal field was taken to be $0.18 \mathrm{~T} / \mathrm{sec}$. Reference 4 studies plasma disruption and arrives at two limits for the time in which the plasma current goes from the steady state to zero. These values are $0.024 \mathrm{sec}$ and $100 \mu \mathrm{sec}$. We can approximate the magnetic field associated with the plasma current by assuming that the current is in the form of a filament at the plasma axis. It should suffice to use a straight filament approximation so that

$$
B=\frac{\mu_{0} I}{2 \pi r}
$$

For the TNS conditions, $I=4.5 \mathrm{MA}$ and $\mathrm{r} \approx 1.5 \mathrm{~m}$, which gives $\mathrm{B}=0.6 \mathrm{~T}$. Thus, we have the following three values of $\dot{B}$ : 


\begin{tabular}{lll} 
& \multicolumn{1}{c}{$\dot{B}$} & \multicolumn{1}{c}{$\tau$} \\
\cline { 2 - 3 } Normal operation & $0.18 \mathrm{~T} / \mathrm{sec}$ & $3.3 \mathrm{sec}$ \\
Least severe disruption & $25 \mathrm{~T} / \mathrm{sec}$ & $0.024 \mathrm{sec}$ \\
Most severe disruption & $6000 \mathrm{~T} / \mathrm{sec}$ & $10^{-4} \mathrm{sec}$
\end{tabular}

It should be borne in mind that for normal operation $\dot{B}$ can be both positive and negative, whereas for disruptions, $\dot{B}$ is only negative. Also given are the corresponding times for field change to be used for evaluation of the governing dimensionless parameters. In order for the solution to be valld, the following conditions must prevail:

$$
\begin{aligned}
& \mathrm{N}=\mathrm{B}_{\mathrm{y}}^{2} \sigma \tau / \rho \gg 1 \\
& M=B_{y} a \sqrt{\sigma / n} \geqslant 1 \\
& \varepsilon=\sigma_{\mathrm{w}} \mathrm{T} / \sigma \mathrm{a} \ll 1 \\
& \mathrm{R}_{\mathrm{m}}=\mu \sigma \mathrm{a}^{2} / \tau \ll 1 \\
& \text { Using } \mathrm{B}_{\mathrm{y}}=6 \mathrm{~T} \\
& \sigma=2.8 \times 10^{6} \mathrm{mho} / \mathrm{m} \quad \eta=3.5 \times 10^{-4} \mathrm{~Pa} \cdot \mathrm{sec} \\
& \rho=500 \mathrm{~kg} / \mathrm{m}^{3} \quad \sigma_{\mathrm{w}}=10^{6} \mathrm{ml} \mathrm{m} / \mathrm{m} \\
& \mathrm{a}=0.05 \mathrm{~m} \cdot \mathrm{T}=0.0016 \mathrm{~m}
\end{aligned}
$$

\begin{tabular}{|c|c|c|c|}
\hline & $\tau=3.33 \mathrm{sec}$ & $0.024 \mathrm{sec}$ & $10^{=4} \mathrm{sec}$ \\
\hline $\mathrm{N}$ & 670,000 & 4,840 & 20.2 \\
\hline$M$ & 26,800 & 26,800 & 26,800 \\
\hline $\mathrm{R}_{\mathrm{m}}$ & 0.0026 & 0.367 & 88 \\
\hline$\varepsilon$ & 0.011 & 0.011 & 0.011 \\
\hline
\end{tabular}

We obtain the following table: 
All the criteria are met except that the value of $R_{m}=0.367$ is marginal and the value of $\mathrm{R}_{\mathrm{m}}=88$ is clearly invalid. Despite this invalidity, several values of pressure, etc., for $\tau=10^{-4} \mathrm{sec}$ will be calculated realizing that these values will be higher than reality.

\subsection{TRANSIENT PRESSURES}

The following expressions describe the nonuniform pressure on the inside of a module at the wall. In both the positive and negative cases of $\dot{B}$, there are regions where $\mathrm{p}-\mathrm{p}_{\mathrm{o}}$ will be negative. This suggests that one criterion for limiting $p-p_{0}$ would be to avoid potential cavitation, which would be possible if absolute pressure became negative.

Coaxial case $p-p_{0}=\frac{1}{8} \sigma a^{2} B_{x} \dot{B}_{x}\left(1-4 \cos ^{2} \beta\right) \quad[E q$. (16) $]$

Noncoaxial case $\mathrm{p}-\mathrm{p}_{\mathrm{o}}=\frac{1}{4} \sigma_{\mathrm{w}} \mathrm{TaB}_{\mathrm{z}} \dot{\mathrm{B}}_{\mathrm{z}}\left(1-4 \cos ^{2} \theta\right) .[\mathrm{Eq} \cdot(10)]$

It suffices to consider only the first expression because it is greater than the second by a factor of 43.8. The following values of $p-p_{0}$ are obtained where only maximum negative values are considered.

\begin{tabular}{|c|c|c|c|}
\hline & $\dot{\mathrm{B}}(\mathrm{T} / \mathrm{sec})=0.18$ & 25 & 6000 \\
\hline Máx Negalive & $204 \mathrm{Fa}$ & $13,100 \mathrm{~Pa}$ & $3.15 \times 10^{\epsilon} \mathrm{Ha}$ \\
\hline Value of $p-p_{0}$ & $(0.041 \mathrm{psi})$ & (1.9 psi) & $(457 \mathrm{psi})$ \\
\hline
\end{tabular}

\subsection{VARIOUS STRESSES IN THE WALL}

For the coaxial case, a torsional moment is produced largely by the interaction of $\mathrm{B}_{\mathrm{y}}$ and currents in the wall. This torsional moment is given by Eq. (18). If we neglect all but the dominant term in the parentheses, 'we have

$$
\mathrm{M}_{\mathrm{7}}^{\mathrm{b}}=\pi \mathrm{TLa}^{3} \sigma_{\mathrm{w}} \mathrm{B}_{\mathrm{y}} \dot{\mathrm{B}}_{\mathrm{x}}
$$


The shear stress due to this torque is treated by elementary strength of materials and turns out to be

$$
\tau=\operatorname{La} \sigma_{w} B_{y} \dot{B}_{x}
$$

The following table results from these two equations (using $L=0.65 \mathrm{~m}$ ).

$$
\begin{aligned}
& \underline{\dot{B}_{x}=0.18 \mathrm{t} / \mathrm{sec}} \quad 25 \quad 6,000 \\
& \begin{array}{llll}
\mathrm{M}_{\mathrm{L}}^{\mathrm{b}} & 0.44 \mathrm{Nm} & 61.3 \mathrm{Nm} & 14,700 \mathrm{Nm} \\
\tau \text { due to } \mathrm{M}_{\mathrm{z}}^{\mathrm{b}} & 35,100 \mathrm{~Pa} & 4.88 \times 10^{6} \mathrm{~Pa} & 1.17 \times 10^{9} \mathrm{~Pa} \\
& (5.1 \mathrm{psi}) & (707 \mathrm{psi}) & (170,000 \mathrm{psi})
\end{array}
\end{aligned}
$$

'l'his last equation for shear stress gives greater values than Eq. (19) for shear stress by the factor $\mathrm{L} / \mathrm{a}=13$.

From Eq. (11) for the noncoaxial case, we have an expression for the bending moment about the $\mathrm{x}$ axis, which is due mostly to body forces resulting from currents in the wall. This is

$$
\mathrm{M}_{\mathrm{x}}^{\mathrm{b}}=\frac{3}{4} \operatorname{ra} \mathrm{a}^{3} \mathrm{TL} \sigma_{w} \mathrm{~B}_{\mathrm{y}} \dot{\mathrm{B}}_{z} \cdot
$$

The resulting bending stress is

$$
\frac{3}{4} \text { La } \sigma_{w} B_{y} \dot{B}_{z}
$$

It may be seen that these bending stresses are three-fourths times the shcar otrecees juet calculated obviating tabulation of these bending stresses.

The change in hoop stress due to hydrodynamic pressures in the coaxial case produces higher values of stress than a similar case for the noncoaxial case [Eq. (12)], and this is given by Eq. (21), namely, 


$$
\Delta \sigma_{\theta}^{h}=\frac{5}{24} \frac{a^{3}}{T} \sigma B_{x} \dot{B}_{x}
$$

which gives the following values:

$$
\begin{aligned}
& \dot{\mathrm{B}}(\mathrm{T} / \mathrm{sec})=0.18 \\
& 25 \\
& 4,000 \\
& \Delta \sigma_{\theta}^{\mathrm{h}} \quad 4921 \mathrm{~Pa} \\
& \text { (0.72 psi) } \\
& 6.84 \times 10^{5} \mathrm{~Pa} \\
& 164 \times 10^{6} \mathrm{~Pa} \\
& \text { (99 psi) } \\
& \text { (24,000 psi) }
\end{aligned}
$$

\subsection{RING BENDING DUE TO NONUNIFORM PRESSURE}

In the noncoaxial case, it was shown that the body forces in the wall combine with the hydrodynamic pressure forces to produce a resultant load on the circular cross section that has axial symmetry, thus producing no bending moment tending to deform the circular cross section; however, this is not true in the coaxial case. Equation (17) is for the body force that will cause bending of the ring-like cross section of the tube. When the maximum value of this force is compared to that for the nonuniform pressure, it is found that it is smaller by a factor of 33 . Thus, the stresses for the ring bending mode will be calculated for the nonuniform pressures with the reasonable expectation that this is a good approximation of the maximum effect. In addition, the maximum value of the nonuniform pressure is a factor of 2000 greater than that for $b_{\theta}$ for the noncoaxial case, suggesting that the stresses due to $b_{\theta}$ can be neglected. The cross section of the cylinder is subjected to a pressure distribution given above for the nonuniform pressure in the coaxial case, where it was used for evaluation of the pressure per se. The distribution is illustrated in F1g. 5.

The bending moments for this ring are statically indeterminate. The problem may be treated by traditional methods that may be found in Ref. 11. There the method of calculation is given for the case of a ring loaded by a force distribution that has symmetry about two axes. That condition is met for our problem. It is pointed out that all quadrants are the same, and so it suffices to treat only one. Such a 


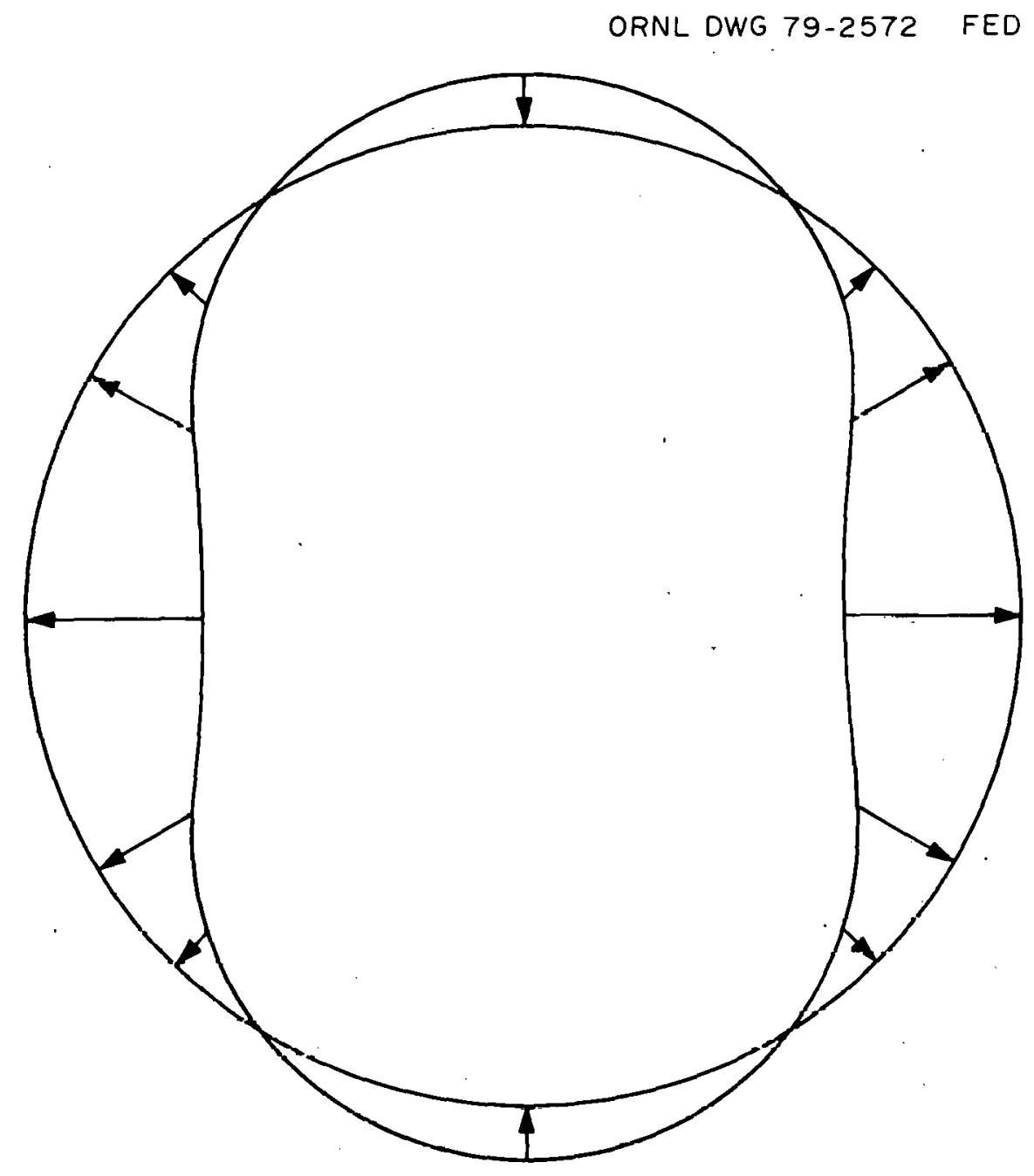

Fig. 5. Nonuniform pressure distribution. 
quadrant is shown in Fig. 6. The load distribution is omitted from the figure for clarity. The radial shear at $\theta=0$ and $\pi / 2$ are both zero by symmetry, and $\mathrm{F}_{\mathrm{y}}$ is determined from static equilibrium. The moment $\mathrm{m}_{\mathrm{a}}$ is statically indeterminate. We can write an expression, which will include $\mathrm{m}_{\mathrm{a}}$, for moment $\mathrm{m}$ at any point. We know that the slope change at $\theta=0$ must be zero. As described in Ref. 11, this slope change involves the elastic properties. Setting the slope change equal to zero, we have

$$
\int_{0}^{\pi / 2} \frac{{ }^{\prime \prime} \mathrm{a}}{E I} \mathrm{~d} \theta=0:
$$

This permits evaluation of $\mathrm{m}_{a}$, and when this is done we find that the bending moment is zero for $\theta=60^{\circ}$ and maximum for $\theta=0$. We then calculate the bending stress for this maximum moment as

$$
\sigma_{b}=1.023 \sigma \frac{a^{4}}{T^{2}} B_{x} \dot{B}_{x}
$$

The following table of bending stresses results:

$$
\begin{array}{llll}
\dot{\mathrm{B}}(\mathrm{T} / \mathrm{sec}) & 0.18 & 25 & 6000 \\
\text { Bending stress } & 755,000 \mathrm{~Pa} & 1.05 \times 10^{8} \mathrm{~Pa} & 2.52 \times 10^{10} \mathrm{~Pa} \\
& (109 \mathrm{psi}) & (15,200 \mathrm{psi}) & \left(3.66 \times 10^{6} \mathrm{psi}\right)
\end{array}
$$

\subsection{SIGNIFICANCE OF THE RESULTS AND SCALING CONSIDERATIONS}

The values of stress for the most severe disruption case are out of reason, but they are known to be overestimates because the value of $\mathrm{R}_{\mathrm{m}} \gg 1$. Conclusive estimates would require further analysis. Mnst of the other results are nearly negligible with the exception of the ring bendiug stress value of 15,200 psi, which is large enough that it could influence design or possible failure. It should be borne in mind that the bending stress of 109 psi cycles from posilive to negative, and so the strain range, which correlates well with fatigue failure, is that 
ORNL DWG 79-2573 FED

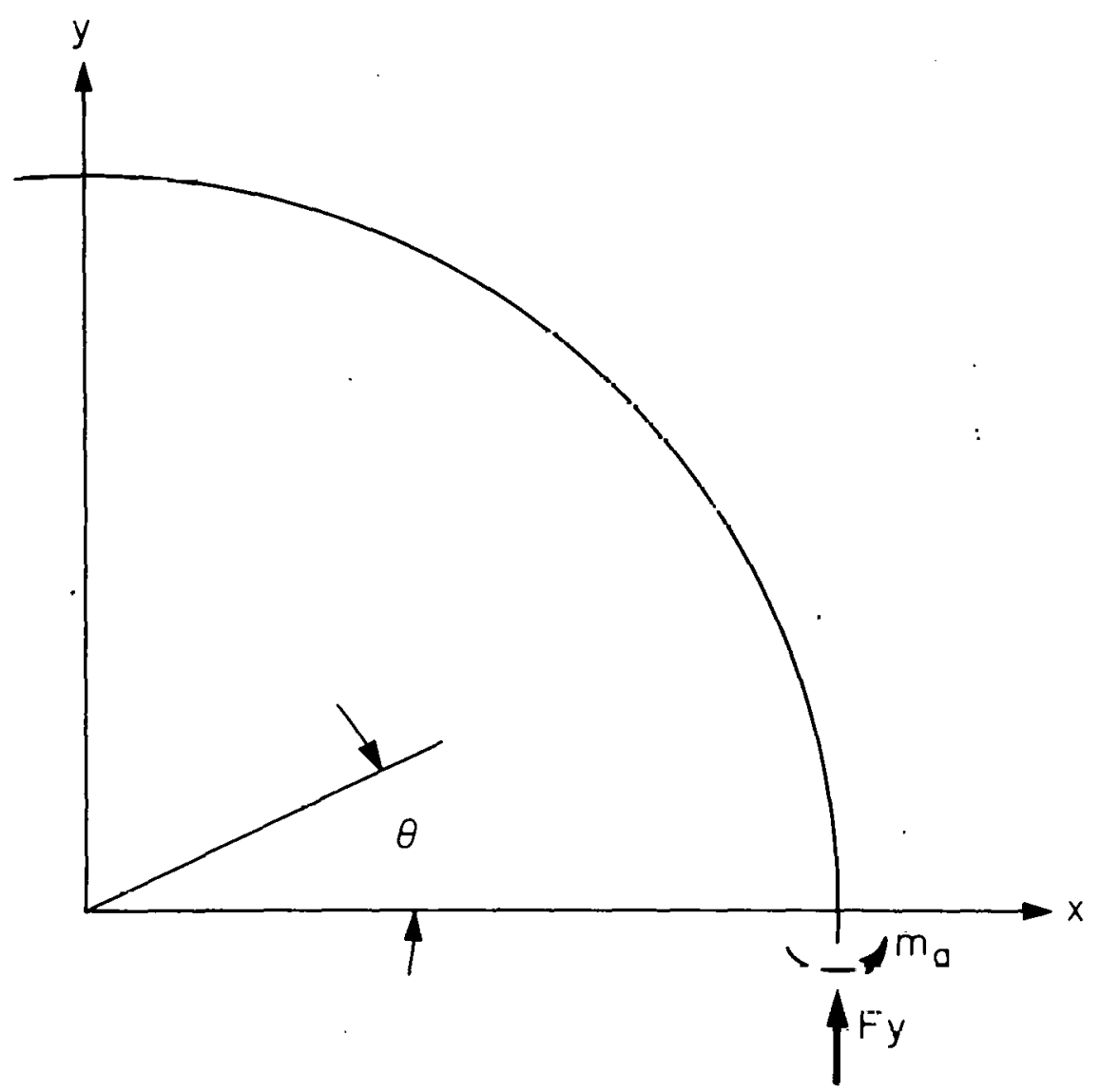

Fig. 6. Quadrant of the ring used for analysis. 
associated with a stress of twice this value. So far, this discussion relates only to the values obtained when $\dot{B}$ and size are as used in Ref. 3.

It is pertinent to consider how scaling occurs. We have already observed what happens when $\dot{B}$ changes - namely, the subject stresses and pressures are proportional to $\dot{B}$. For all the pressures and stresses dealt with here, the values go as the square of linear dimension. The following suggestions appear reasonable.

A number of blanket designs involve modules that have minimum dimensions almost equal to the blanket thickness, which means that the dimensions scale upward from our value of " $\mathrm{a}$ " by about a factor of 10; thus, the pressures increase by a factor of 100. This gives pressures for normal operation that fluctuate by $u \pm 4$ psi, which should not create a cavitation problem but probably would be troublesome if the construction consisted of thin flat members. If, on the other hand, the modules were cylindrical, then we should look at the ring bending stresses above. We note that this bending stress goes as $a^{4} / T^{2}$. In regions of the blanket near the plasma, it is expected that thickness will be limited to about twice the value we used or $0.0032 \mathrm{~m}$. Any greater thickness is apt to cause difficulty with thermal stresses and/or temperature levels due to surface heat flux and radiation heating in the metal. If we assume this factor of 2 increase in $\mathrm{T}$, but a factor of 10 increase in "a," this scaling relation leads to an increase in the stress level by a factor of $10^{4} / 2^{2}=2500$, resulting in a stress level of $\pm 109 \times 2500= \pm 273,000$ psi. From a practical standpoint, this appears to be the most important consequence of this paper. 
THIS PAGE

WAS INTENTIONALLY

LEFT BLANK 


\section{END EFFECTS}

The analyses presented in Sects. 2, 3, and 4, as well as the numerical examples presented in Sect. 5, assume that the liquid metal is contained in an infinitely long, constant cross section, circular pipe. Real containers, such as the cylinder shown in Fig. 2, have finite lengths. If the actual container is sufficiently long, there is a central region away from the ends where the flow is accurately described by the solutions that are presented in Sects. 3 and 4 and solutions that are independent of $z$; there are two regions near the ends in which the flow is three-dimensional and the variables are functions of $z$, as well as $\mathrm{x}$ and $\mathrm{y}$. In order to model the cylinder shown in Fig. 2, we treat a container consisting of a circular pipe of length $\mathrm{L}$, which is otherwise the same as the infinitely long pipe described in Sect. 2 (see Fig. 7). At one end, there is a hemispherical cap with the same râdius, thickness, and electrical conductivity as the pipe, and at the other end, there is a metal plug with a length comparable to the radius, a, and with an electrical conductivity, $\sigma_{p}$, comparable to the fluid, $\sigma$. The coordinate system is the same as that shown in Fig. 3, where the origin is at the center of the hemisphere.

For the time-dependent, transverse magnetic field (coaxial case), the effects of the ends turn out to be simple and negligible. For the core solution presented in Sect. 4, the fluid motion is a simple rigidbody rotation with a dimensionless angular velocity, $\omega=-v_{\theta} / r=\dot{\dot{f}}(t) F^{2}(t)$. l'he applied magnetic field is rotating in the same direction with a dimensionless angular velocity,

$$
\mathrm{d} / \mathrm{dt}(\arctan f)=\dot{\mathrm{f}}(t) \mathrm{F}^{2}(t)
$$

so that the fluid is rotating with the magnetic field. An analysis of the flow in the finite-length container for the coaxial case reveals that the velocity is independent of $z$ everywhere and that all of the fluid moves as a single rigid body with angular velocity $\omega$ about the $z$ axis. 
ORNL-DWG $79-2574 \quad$ FED

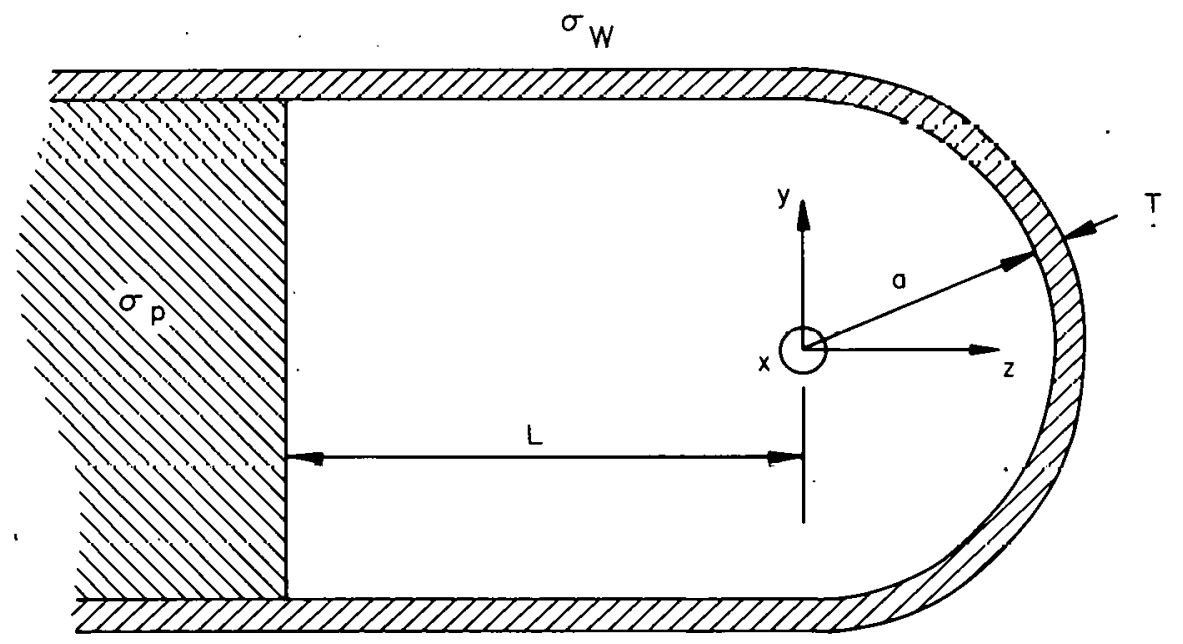

Fig. 7. Section at $\mathrm{x}=0$ of pipe with hemispherical cap and metal plug used to model blanket module. 
The only nonzero electrical current in the solution presented in Sect. 4 for the coaxial case is

$$
j_{z}=X \sigma B^{-1} B_{x} \dot{B}_{x}
$$

so that, away from the ends, current flows in the $+z$ direction for $\mathrm{X}>0$ and in the $-z$ direction for $X<0$, where the $X, Y$ coordinates are shown in Fig. 4. Clearly, there must be a completion of the electrical circuit at each end. At the plug end, the circuit is completed inside the plug with a negligible effect on the fluid variables. There is, of course, a body force inside the plug due to the current flowing out of and then back into the fluid. Inside the hemispherical end, current follows the cylindrical surfaces that are concentric with the $\mathrm{Y}$ axis, thus completing the circuit here. The pressure is constant on the cylindrical surfaces and is continuous at $z=0$. Therefore, for the coaxial case, end effects are confined to the plug and the interior of the hemispherical cap and are simple modifications of the solutions for infinite pipes.

For the time-dependent, axial magnetic field (noncoaxial case), the end effects are more complex and more significant. Analyses for the plug and hemispherical ends are very similar, and so only the analysis for the hemispherical end is presented here. The dimensionless equations governing the core variables are Eqs. $(1 \mathrm{~b}, \mathrm{c}, \mathrm{e}, \mathrm{g})$ and

$$
\underset{m}{\nabla p}=\underset{m}{j} \times \underset{m}{B}
$$

where $\underset{m}{B}=\hat{y}_{m}+f(t) \underset{m}{\hat{z}}$, as in Sect. 3. If $\underset{m}{E}=y \dot{f}(t) \underset{m}{\hat{x}}+e_{m}$ is introduced into $\mathrm{Eq} \cdot(1 \mathrm{~g})$, the result is $\underset{m}{\nabla} \times \underset{m}{e}=0$, and an electric potential function, $\phi$, can be introduced so that $\underset{m}{e}=-\underset{m}{\phi}$, or

$$
\underset{m}{E}=y \dot{f}(t) \hat{x}-\nabla \phi
$$

As in Sect. 4, we use rotating cartesian coordinates $(\mathrm{X}, \mathrm{Y}, \mathrm{Z})$, which now rotate about the $x$ axis so that the $Y$ axis is always parallel to $\mathrm{B}_{m}$, as shown in Fig. 8. Once again, $\mathrm{B}_{m}=F^{-1}(t) \underset{m}{\hat{Y}}$, where $F=\left(1+f^{2}\right)^{-1 / 2}$, 
ORNL-DWG 79-2575 FED

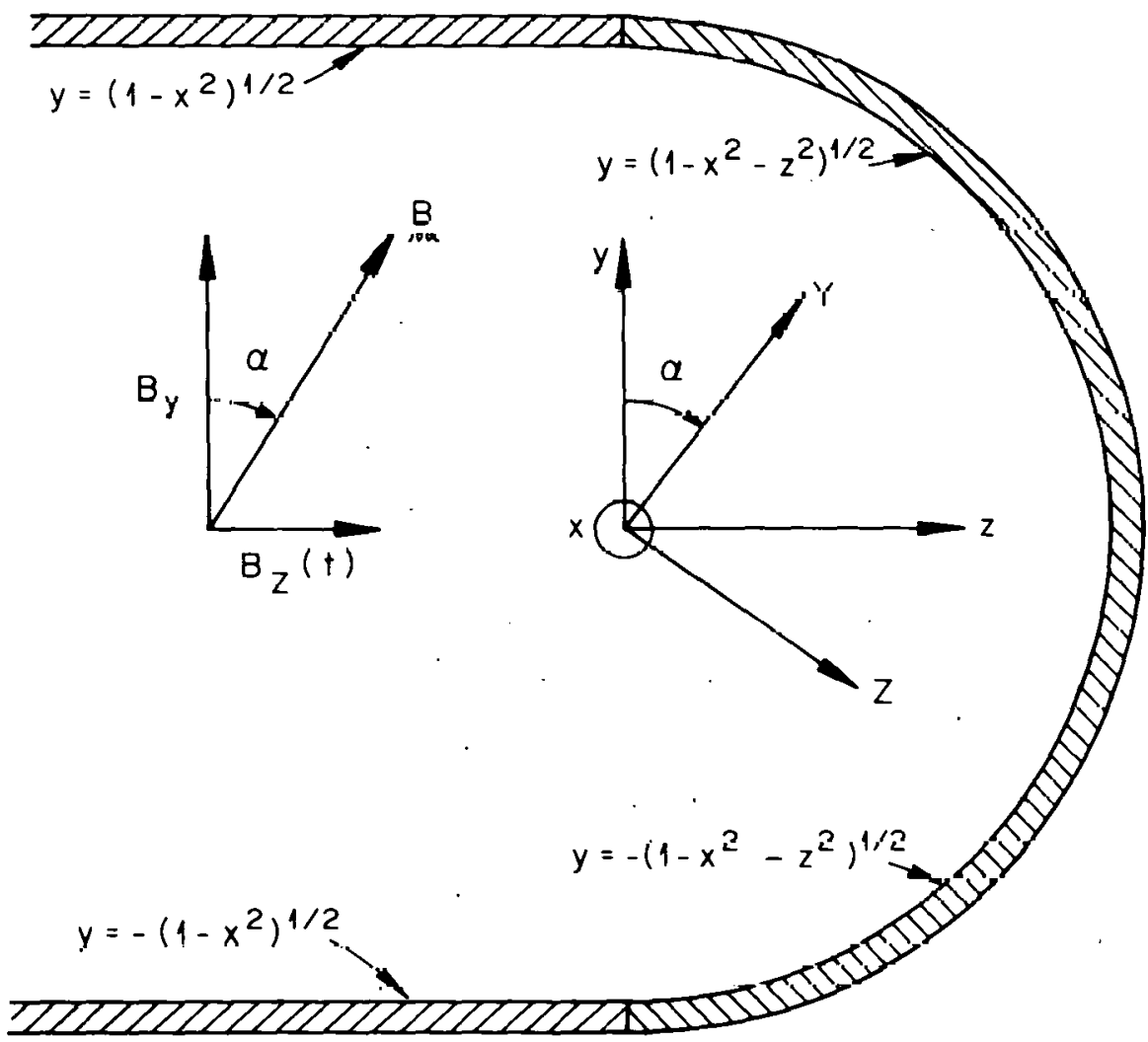

Fig. 8. Section at $x=0$ showing coordinates for analysis of end effects with time-dependent axial magnetic field. 
and the angle of rotation, now about the $\mathrm{x}$ axis, is $\alpha=\operatorname{arc} \tan \mathrm{f}$, relative to the fixed $x, y, z$ coordinates. The $Y$ and $z$ components of the velocity and electric current density measured by a fixed observer are denoted by $V, W, j_{Y}$, and $j_{Z}$. Note that $V$ and $W$ are quite different from the components of the velocity measured by an observer rotating with the $\mathrm{X}, \mathrm{Y}, \mathrm{Z}$ coordinates.

The $\mathrm{Y}$ component of Eq. (22) indicates that $\mathrm{p}$ is independent of $\mathrm{Y}$, and the $x$ and $z$ components are

$$
j_{Z}=-F \partial p / \partial x, \quad j_{x}=F \partial p / \partial z,
$$

respectively. Introducing these equations into $\mathrm{Eq}$. (1c), we find that $j_{Y}$ is also independent of $Y$. The boundary condition on the current is $j_{m} \cdot \hat{n}=0$ at the inside surface of either the pipe or the hemisphere, neglecting $O\left(\varepsilon, M^{-1}\right)$ terms, where $\hat{\mathfrak{n}}$ is a unit normal to the surface. If we consider a line $\left(x_{0}, z_{0}\right)$ between its intersections with the pipe or hemisphere, the vector $j_{\mathrm{m}}$ is the same vector at every point along the line since $\underset{m}{j}$ is independent of $Y$. The boundary condition on $\underset{m}{j}$ indicates that it must be tangent to each wall at the two intersections. Thus, $j$ on this line is parallel to the pair of parallel tangents to the wall at the two intersections of the line and the wall. This pair of parallel tangents defines a segment of a surface composed of lines that are parallel to the $Y$ axis and lines that have the same length, $\gamma$, inside the container, i.e., with the same distance between the intersections with the wall. Consiciering $\underset{m}{j}$ and its boundary condition at successive lines along this and successive surface segments defines a characteristic surface with constant $Y$ distance between the intersections of the surface and the wall. The current $j$ follows this surface and is parallel to its intersections with the wall, while the pressure is constant on this surface.

Views of several characteristic surfaces looking in the $+x$ and $-Y$ directions are presented in Fig. 9. In region $I$, for $f F\left(1-x^{2}\right)^{1 / 2} \leqslant$ $z \leqslant\left(1-x^{2}\right)^{1 / 2}$, the characteristic surfaces intersect the hemisphere at both the top and bottom, so that the surfaces are concentric cylinders 


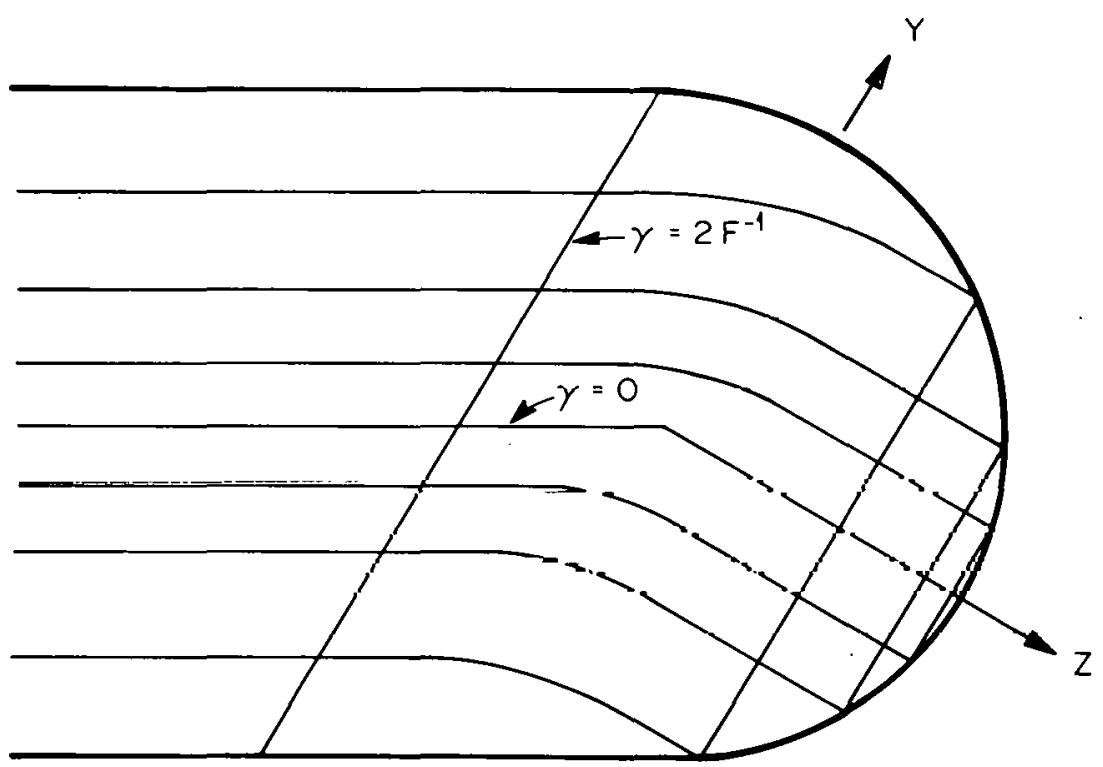

(a)

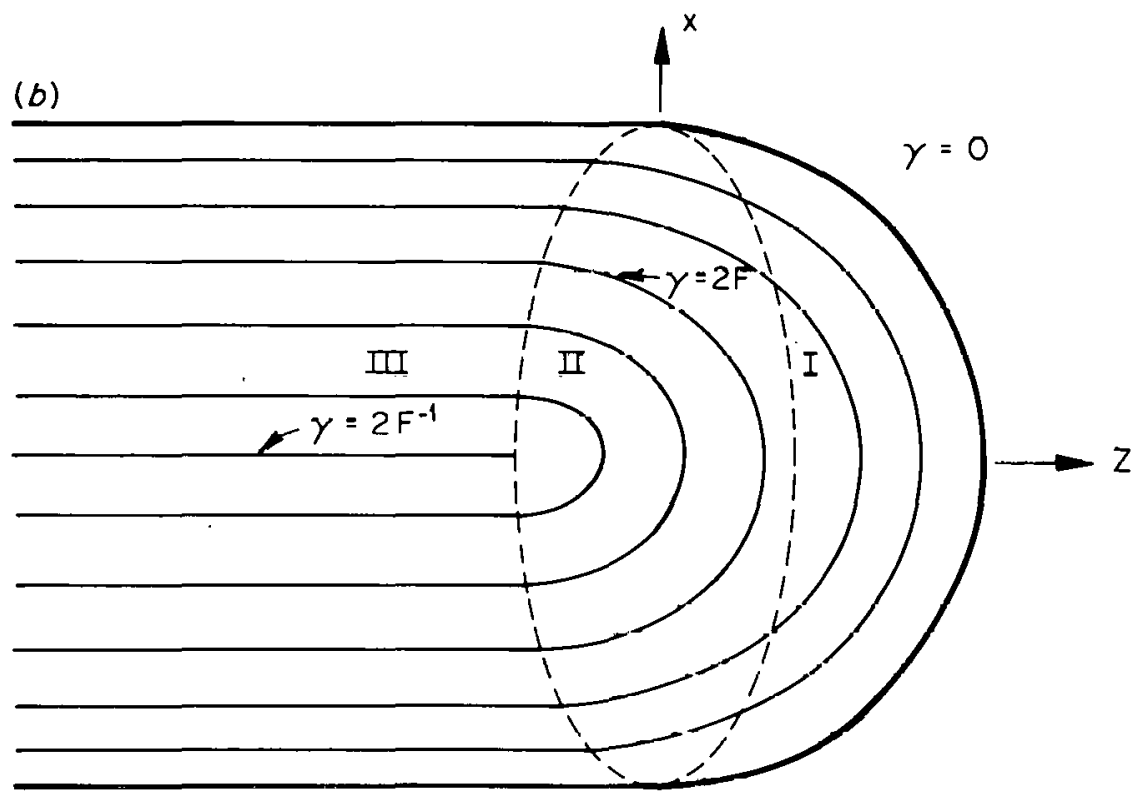

Fiy. 9 (a) View of characterlet1c surfaces looking in $+x$ direction. (b) View of characteristic surfaces looking in $-Y$ direction. Dashed ellipse at $Z= \pm f F$ $\left(1-x^{2}\right)^{1 / 2}$ separates region $I$, where surfaces are cylinders concentric with the $Y$ axis, region II, where surfaces are given by complex equations, and region III, where surfaces are planes parallel to the $Y, Z$ plane. Surfaces with $2 F \leqslant \gamma \leqslant 2 F^{-1}$ never enter region $I$. 
with a $Y$ axis. In region II, for $|Z|<f F\left(1-x^{2}\right)^{1 / 2}$, the characteristic surfaces intersect the hemisphere at the top and the pipe at the bottom, so that the surfaces are defined by constant values of the function

$$
\gamma=\left(1-x^{2}-z^{2}\right)^{1 / 2}-f Z+F^{-1}\left(1-x^{2}\right)^{1 / 2}
$$

In region III, for $Z \leqslant-f F\left(1-x^{2}\right)^{1 / 2}$, the characteristic surfaces intersect the pipe at both the top and bottom, so that the surfaces are planes parallel to the $y, z$ plane.

The value of the pressure on and the amount of current flowing along each characteristic surface are determined by conditions away from the end, i.e., as $z \rightarrow-\infty$, ignoring the other end. The infinite-pipe solution, presented in Sect. 3, indicates that the current along the surfaces $j_{2}=0$, and neglecting $O(\varepsilon)$ terms, the pressure is constant. However, it turns out that there is a long, $O\left(\varepsilon^{-1 / 2}\right)$ length of pipe in which the flow deviates from the infinite-pipe flow and in which $j_{z}$ and $\partial \mathrm{p} / \partial \mathrm{x}$ are $O\left(\varepsilon^{1 / 2}\right)$, as we will see later. Therefore, in regions I, II, and III, $j_{m}=0$ and $p$ is constant, neglecting $O\left(\varepsilon^{l / 2}\right)$ terms.

With $\underset{m}{j}=0$, the $\mathrm{Y}$ component of $\mathrm{Eq}$. (le) indicates that $\phi$ is independent of $\mathrm{Y}$, and the $\mathrm{x}$ and $\mathrm{Z}$ components are

$$
W=\dot{f} F^{2}(Y-f Z)-F \partial \phi / \partial x, u=F \partial \phi / \partial Z,
$$

respectively. These equations are introduced into Eq. (lb), which is then integrated to obtain

$$
V=Y \dot{f} f F^{2}+H(x, Z, t)
$$

Equations $(25,26)$ neglect $O\left(\varepsilon^{1 / 2}\right)$ terms.

The boundary condition on the velocity is $\underset{m}{\mathrm{v}} \cdot \hat{\mathfrak{n}}=0$ at the wall. For the pipe, 
$0=\underset{m}{v} \cdot \underset{m}{\hat{n}}=-x u \pm\left(1-x^{2}\right)^{1 / 2} F(V-f W)$, at $Y=f Z \pm F^{-1}\left(1-x^{2}\right)^{1 / 2}$,

and for the hemisphere,

$0=v \cdot \hat{m}=-x u-Z W \pm\left(1-x^{2}-z^{2}\right)^{1 / 2} V$, at $Y= \pm\left(1-x^{2}-z^{2}\right)^{1 / 2}$.

For region 1 , both of the conditions [Eq. (28)] are applied to the solutions [Eqs. $(25,26)$ ], giving two equations. If these equations are subtracted from and added to each other, the results are

$$
\begin{aligned}
& H=-\dot{f} F^{2} Z, \\
& Z \partial \phi / \partial x-x \partial \phi / \partial z=\dot{f} f F\left(1-x^{2}-2 Z^{2}\right),
\end{aligned}
$$

respectively. The cylindrical coordinates, $\mathrm{R}, \lambda, \mathrm{Y}$, are shown in Fig. 10. In these coordinates, Eq. (29b) is

$$
\partial \phi / \partial \lambda=\dot{\operatorname{fffF}}\left[\left(1-3 R^{2} / 2\right)-\left(R^{2} / 2\right) \cos 2 \lambda\right]
$$

In region $I$, the characteristic surfaces are the cylinders $R=(1-$ $\left.\gamma^{2} / 4\right)^{1 / 2}$, so Eq. (30) gives the derivative of $\phi$ along each characteristic surface. By symmetry, $u=0$ at $x=0$, so Eq. (25b) indicates that $\partial \phi / \partial \ddot{Z}=0$ at $x=0$. This gives the boundary condition

$$
\phi=n \text {, at } \lambda=n \text {, }
$$

where an inessential integration function of $t$ has been dropped. Integrating Eq. (30) from $\dot{\lambda}=0$ now gives

$$
\phi=\dot{\operatorname{fff}} \mathrm{F}\left[\left(1-3 R^{2} / 2\right) \lambda-\left(R^{2} / 4\right) \sin 2 \lambda\right] .
$$




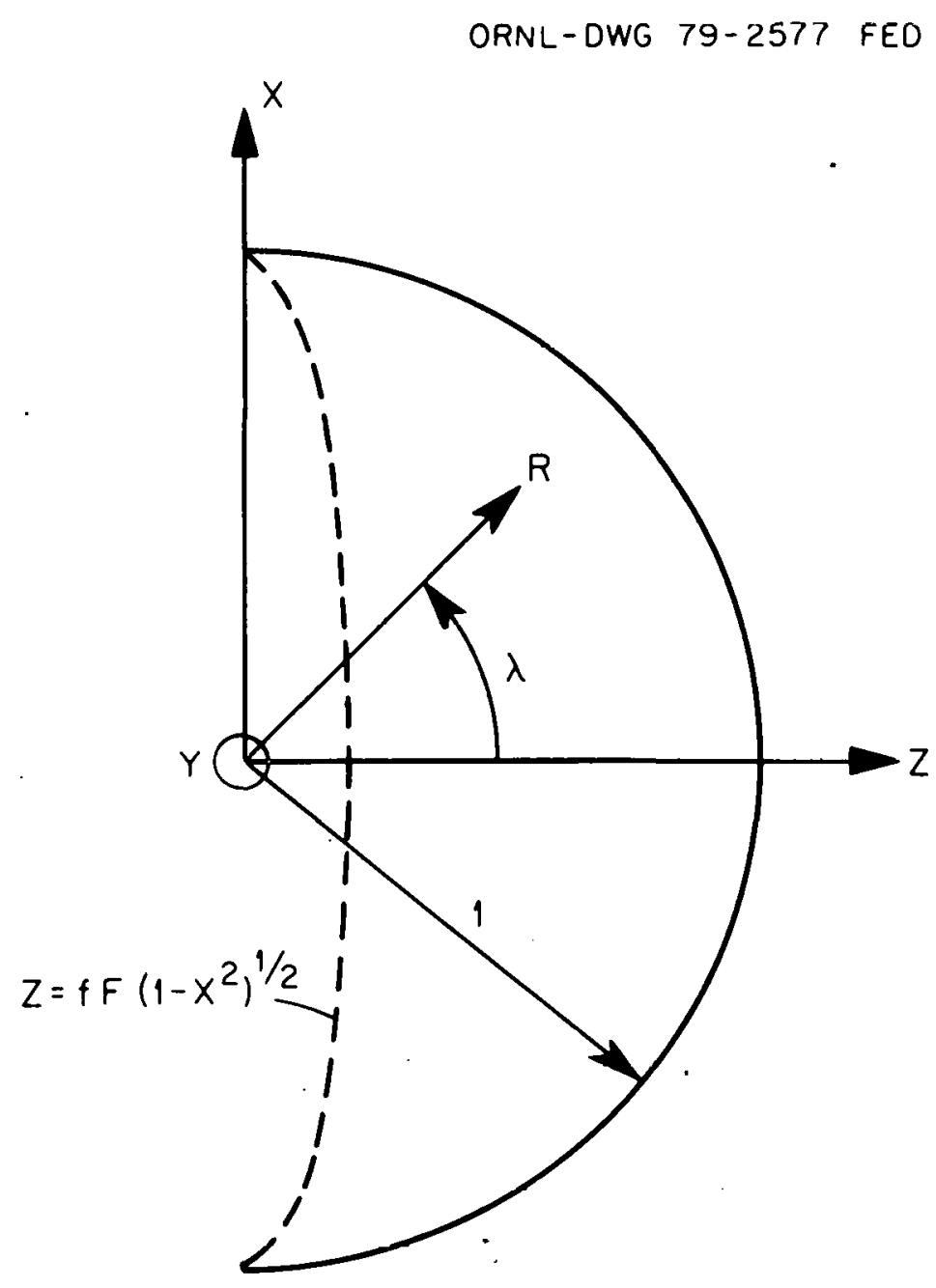

Fig. 10. Cylindrical coordinates $R, \lambda, Y$ for region $I$. Characteristic surfaces are cylinders with $R=$ constant and $\gamma=2\left(1-R^{2}\right)^{1 / 2}$. 
The velocity in region $I$ is now given by Eqs. $(25,26,29 a, 31)$. This velocity is most easily expressed in its components in the cylindrical coordinates, namely,

$$
\begin{aligned}
& V_{R}=\dot{\mathrm{f}} F^{2}\left[\mathrm{Y} \cos \lambda-\mathrm{f}\left(1-\mathrm{R}^{2}\right) / \mathrm{R}\right], \\
& \mathrm{V}_{\lambda}=-\dot{\mathrm{f}} \mathrm{F}^{2}[\mathrm{Y} \sin \lambda+3 \mathrm{fR} \lambda], \\
& V_{Y}=V=\dot{\mathrm{f}} \mathrm{F}^{2}(\mathrm{fY}-\mathrm{R} \cos \lambda) .
\end{aligned}
$$

Velocity vectors are plotted to scale in Fig. 11 in the $\mathrm{Y}=0$ plane (1) at $\mathrm{R}=0.25,0.5,0.75,1.0$ and $\lambda=0^{\circ}, 15^{\circ}, 30^{\circ}, 45^{\circ}, 60^{\circ}, 75^{\circ}$ and (2) at $R=1.0$ and $\lambda=90^{\circ}$. Velocities at other radii at $\lambda=90^{\circ}$ are not given because these points are not in region $I$. Similarly, for the point $\mathrm{R}=0.25, \lambda=0^{\circ}$ to be in region $\mathrm{I}$, $\mathrm{f}$ must be $\leqslant(15)^{-1 / 2}=0.258$. Fluid enters region I from region II for $I>|x|>x_{0}$, and an equal amount of fluid enters region II from region I for $|x|<x_{0}$, where $x_{0}$ is a function of $\mathrm{f}$ and $\mathrm{Y}$.

For region II, the first of the conditions [Eq. (28)] for the intersection with the hemisphere at the top and the second of the conditions [Eq. (27)] for the intersection with the pipe at the bottom are applied to Eqs. $(25,26)$, to obtain two equations involving $\phi$ and $\mathrm{H}$. We eliminate $\mathrm{H}$ by adding $\left(1-\mathrm{x}^{2}\right)^{1 / 2}$ times the first equation (top) to $\left(1-x^{2}-z^{2}\right)^{1 / 2}$ times the second equation (hottom), and we obtain a rather complex expression involving $\partial \phi / \partial x$ and $\partial \phi / \partial z$. In order to interpret this expression, we consider a curvilinear coordinate, $T$, which is measured along each characteristic surface shown in Fig. 9b with $\mathrm{T}=0$ at $\mathrm{x}=0$ and the sign of $\mathrm{T}$ equal to the sign of $\mathrm{x}$. In region $I, T=R \lambda$ on each surface, $R=$ constant. In region $I I$, the derivative of $\phi$ per unit distance along a characteristic surface is $\partial \phi / \partial T=\hat{T} \cdot{ }_{m} \phi$, where the unit vector, $\underset{m}{\hat{T}}$, is tangent to the characteristic surfaces and is given by 


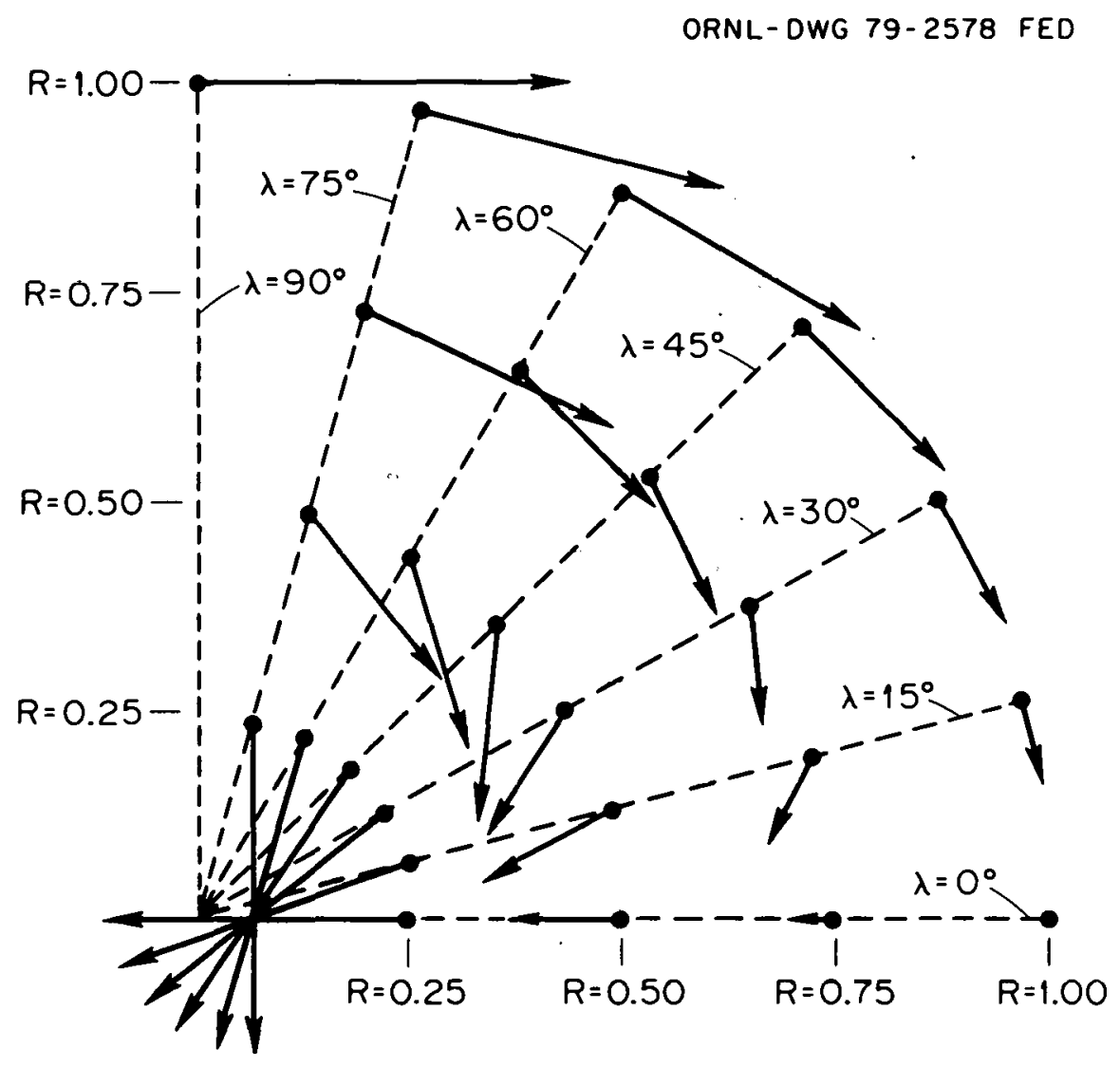

Fig. 11. Velocity vectors in the $Y=0$ plane for region $\mathrm{I}$. Scale for $\mathrm{v} / \mathrm{f}^{\prime} \mathrm{fF}^{2}$ is $0.5 \mathrm{in.}=1$. 


$$
\hat{\mathrm{T}}=-\hat{\mathrm{Y}}_{m} \times \underset{m}{\nabla} / \mathrm{Q},
$$

where the function $\gamma(x, Z)$ is given by Eq. (24) and $Q=\left|\nabla_{m} \gamma\right|$. We find that the expression for $\partial \phi / \partial T$ in terms of $\partial \phi / \partial x$ and $\partial \phi / \partial Z$, which we obtained from the definition [Eq. (24)] of the characteristic surfaces, is exactly the same as the expression involving $\partial \phi / \partial x$ and $\partial \phi / \partial z$, which we obtained by eliminating $\mathrm{H}$ from the equations given by the boundary conditions at the top and bottom; so the final result of the boundary conditions is

$$
A \phi / A \mu=\dot{f} H^{\prime}\left[\left(1-t^{2}\right) z+ \pm\left(1-x^{2}-z^{2}\right)^{-1 / 2}\left(1-x^{2}-2 z^{2}\right)\right] / Q \text {. }
$$

For the characteristic surfaces with $2 \mathrm{~F}<\gamma<2 \mathrm{~F}^{-1}$, the initial value is $\phi=0$ at $I=0$. For $\gamma<2 F$, the initial values of $\phi$ at $T=R_{0} \lambda_{0}$ are obtained by evaluating Eq. (31) at $\lambda=\lambda_{0}=\operatorname{arc} \cos \left[f\left(1-R_{0}^{2}\right)^{1 / 2} / R_{0}\right]$ and $R=R_{0}=\left(1-\gamma^{2} / 4\right)^{1 / 2}$. Equation (33) can now be integrated numerically along each characteristic surface defined by Fq. (24) to obtain the value of $\phi$ at each point in region II. Finally, either of the equations resulting from the boundary conditions at the top and bottom gives $\mathrm{H}$, and Eqs. $(25,26)$ give the velocity. The numerical analysis is straightforward, and the velocity merely transfers the flow between regions I and III without significantly changing the flow patterns for region I; so detailed results for region II are not presented here. One detail about region II warrants further consideration. The expression [Eq. (32a)] for $V_{R}$ in the region $I$ behaves like $R^{-1}$ as $R \rightarrow 0$. Because the line $R=0$ is in region $I I$, the velocity is finite everywhere in region $I$. However, the question remains whether the flow continues to focus into a line in region II or whether it turns from the radial to the axial direction inside region $I I$, entering region III with finite velocity. The potentially singular line in region II is not at $R=0$ but at $z=-f F, x=0$, where the characteristic surface, $\gamma=2 F^{-1}$, abruptly ends. In order to investigate the solution near this 1 ine, we stretch the local coordinates by introducing 


$$
\nu=x / \delta, \quad \xi=(z+f F) / \delta,
$$

where $\delta \ll 1$. We find that Eqs. $(24,33)$ then give

$$
\begin{aligned}
& \gamma=2 \mathrm{~F}^{-1}-\delta^{2} \mathrm{~F}^{-1}\left(\nu^{2}+\xi^{2} / 2 \mathrm{~F}^{2}\right), \\
& Q=\delta \mathrm{F}^{-1}\left(4 \nu^{2}+\xi^{2} / \mathrm{F}^{4}\right)^{1 / 2}, \\
& \partial \phi / \partial \mathrm{T}=\dot{\mathrm{f}} \xi\left(4 \mathrm{~F}^{4} \nu^{2}+\xi^{2}\right)^{-1 / 2,}
\end{aligned}
$$

neglecting $O\left(\delta^{3}\right), O\left(\delta^{2}\right)$, and $O(\delta)$ terms, respectively. The intersection of the characteristic surface,

$$
\gamma=2 \mathrm{~F}^{-1}-\delta^{2} \mathrm{~F}^{-1} \Gamma^{2}
$$

and the $\mathrm{Y}=0$ plane is half an ellipse with a semiminor axis in the $v$ direction equal to $\Gamma$ and a semimajor axis in the $\xi$ direction equal to $2^{1 / 2} \Gamma F$, as shown in Fig. 12. Each ellipse can be represented parametrically in terms of the angle $\Lambda$ by

$$
\nu=\Gamma \sin \Lambda, \quad \xi=2^{1 / 2} \Gamma F \cos \Lambda
$$

The distance along the ellipse $\mathrm{dT}$ corresponding to a change in angle $\mathrm{d} \Lambda$ is given by

$$
\mathrm{dT}=\delta \Gamma\left(\cos ^{2} \Lambda+2 \mathrm{~F}^{2} \sin ^{2} \Lambda\right)^{1 / 2} \mathrm{~d} \Lambda
$$

Using these expressions for $\nu, \xi$, and $d T, E q$. (34c) can be converted into an ordinary differential equation with respect to the parameter $\Lambda$ for each ellipse, namely,

$$
\mathrm{d} \phi / \mathrm{d} \Lambda=\delta \Gamma \dot{\mathrm{f}} \cos \Lambda .
$$




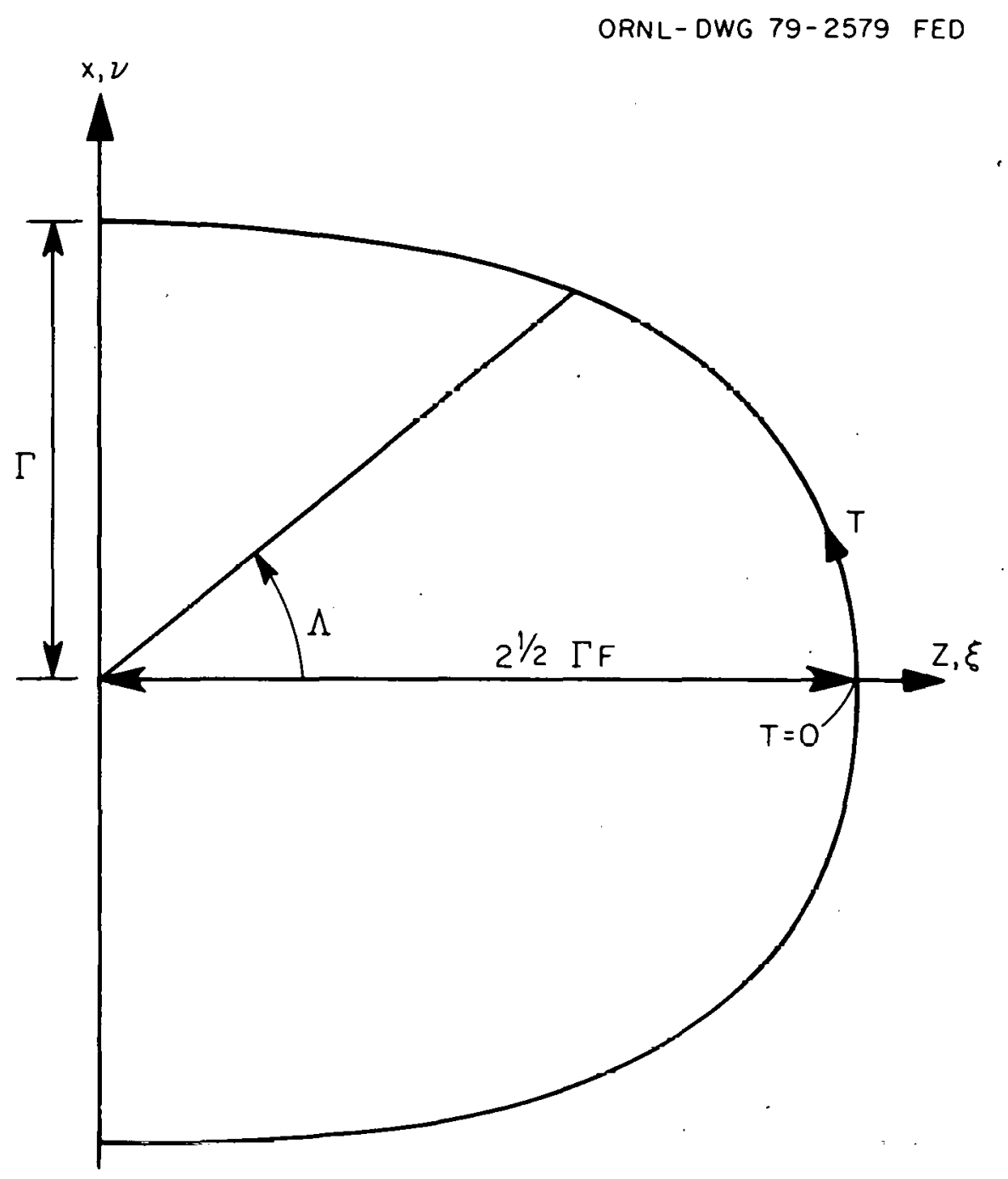

Fig. 12. Semi-ellipse that is the intersection of a characteristic surface near the $x=0, Z=-f F$, and the $\mathrm{Y}=0$ plane. 
This can be integrated to obtain

$$
\phi=\delta \Gamma \dot{\mathrm{f}} \sin \Lambda=\delta \nu \dot{\mathrm{f}}=\mathrm{x} \dot{\mathrm{f}}
$$

neglecting $O\left[x^{2},(f F+z)^{2}\right]$ terms. Therefore, the velocity is finite everywhere in region $I I$, and the flow turns from the radial to the axial direction inside region II, entering region III without any singularities.

For region III, both of the boundary conditions [Eq. (27)] are applied to Eqs. $(25,26)$, giving two equations. If these equations are added to and subtracted from each other, the results are

$$
\partial \phi / \partial Z=0, \quad H=-\dot{\mathrm{f}} \mathrm{f}^{2} \mathrm{~F}^{2} \mathrm{Z}-\mathrm{f} \mathrm{F} \partial \phi / \partial \mathrm{x},
$$

respectively. Equation (35a) indicates that $\phi$ is constant on each characteristic surface $x= \pm\left(1-F^{2} \gamma^{2} / 4\right)^{1 / 2}$, and the values are determined by the values of $\phi$ in region II, evaluated at $Z=-f F\left(1-x^{2}\right)^{1 / 2}$. However, $\phi=0$ in the solution for the infinitely long pipe, and, ignoring the other end, we expect the three-dimensional solution to approach the infinite-pipe solution as $z \rightarrow-\infty$, but the solution for $\phi$ in region III does not approach zero as $z \rightarrow-\infty$. The only nonzero component of velocity in both region III and the infinitely long pipe is $w$, and the $w$ in region III minus that in the infinite pipe is a disturbance velocity due to end effects, $-\partial \phi(x, t) / \partial x$. This involves a flow in the is directiun hear $\mathrm{x}= \pm 1$ and in the $-z$ direction near $\mathrm{x}=0$; the analysis for region III indicaies that this flow never leaves the characteristic surfaces. Clearly, another region exists between region III and the part of the pipe where the flow is the same as that in an infinitely long pipe. In this region, fluid must flow across the characteristic surfaces in order to close the streamlines for the disturbance velocity (see Fig. 13). If the length of this region is $D$, then the velocity normal to the characteristic surfaces, $u$, is $O\left(D^{-1}\right)$. However, we have seen that in the absence of an electrical current along the surfaces, the velocity in a straight pipe is tangent to these surfaces; so this rilrrent, $j_{z}$, muet also be $0\left(D^{-1}\right)$. Decause $j_{z}-0$ in the solution for 
ORNL-DWG 79-2580 FED

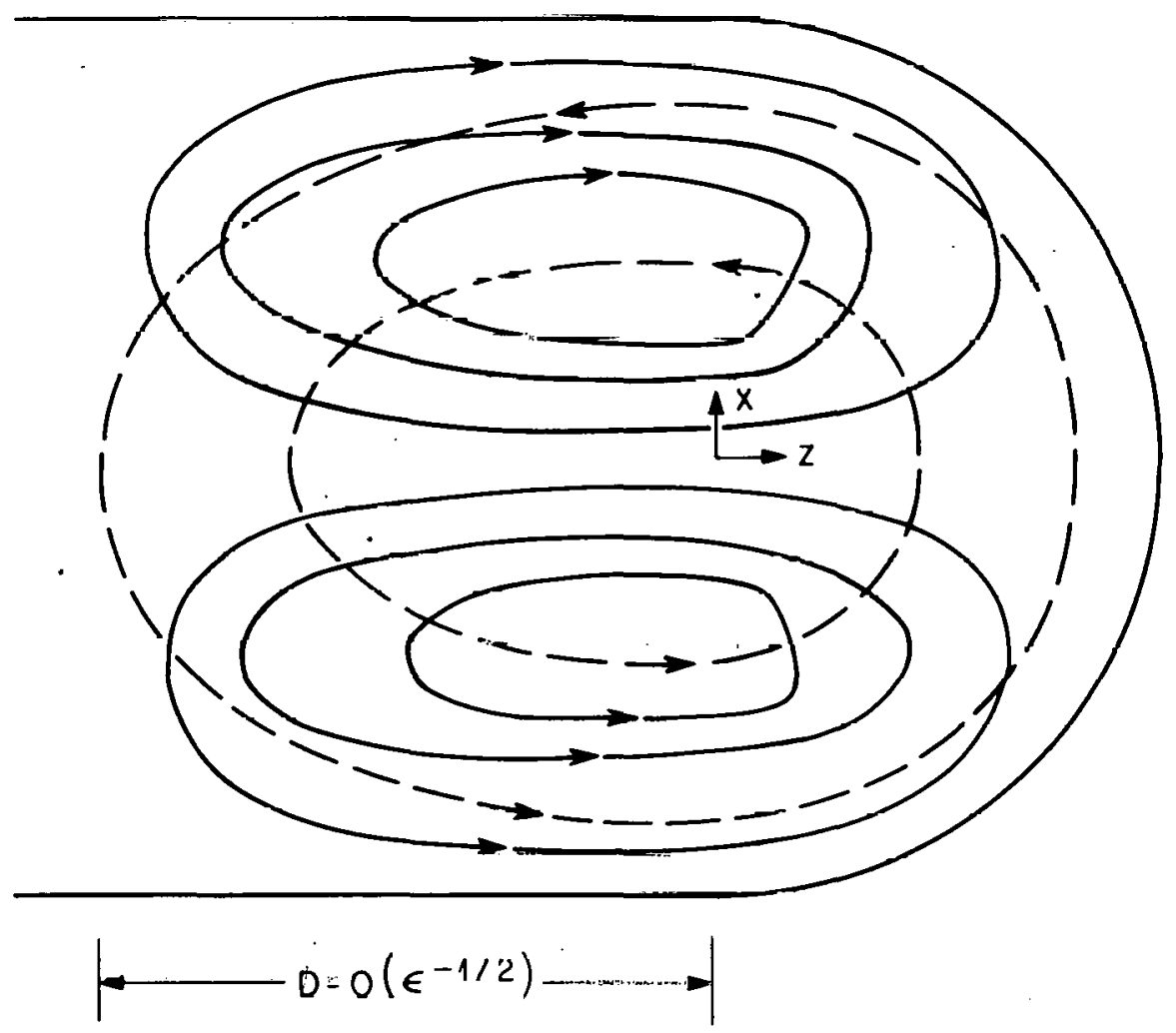

Fig. 13. Sketch in the $y=0$ plane of the streamlines (solid lines) for the $O(1)$ disturbance velocity due to end effects and of the current lines (dashed lines) for the associated $O\left(\varepsilon^{1 / 2}\right)$ electric current. 
the infinitely long pipe, the circuit for this current must be closed inside this region, so that the current normal to the surfaces, $j_{x}$, must be $O\left(D^{-2}\right)$. However, we have also seen that the current normal to the characteristic surfaces must be zero, neglecting $O(\varepsilon)$ terms, so that $D$ must be $O\left(\varepsilon^{-1 / 2}\right)$. In other words, the disturbance created by the hemispherical end decays slowly over a long, $O\left(\varepsilon^{-1 / 2}\right)$ length of pipe.

In order to treat this slow decay, we compress the axial coordinate by introducing $\zeta=\varepsilon^{l / 2} z$. The leading terms in the asymptotic expansions for the variables are $u_{1 / 2}, v_{1 / 2}$, wo, $\phi_{0}, j_{x_{1}}, j_{y_{1}}, j_{z_{1} / 2}$, and $p_{1 / 2}$, where the subscripts $0,1 / 2$, and 1 denote $O(1), O\left(\varepsilon^{1 / 2}\right)$, and $O(\varepsilon)$ terms, respectively. The y component of Eq. (22) indicates that $\mathrm{p}_{1 / 2}$ is independent of $y$, and the $x$ and $z$ components are

$$
j_{z_{1} / 2}=-\partial p_{1 / 2} / \partial x, \quad j_{x_{1}}=\partial p_{1 / 2} / \partial \zeta
$$

respectively. Similarly, the y components of Eqs. (1e,23) indicate that $\phi_{0}$ is independent of $y$, and the $x$ and $z$ components give

$$
w_{0}=y \dot{f}-\partial \phi_{0} / \partial x, \quad u_{1 / 2}=\partial \phi_{0} / \partial \zeta-\partial p_{1 / 2} / \partial x
$$

respectively. Equation (1c) now indicates that $j_{y_{1}}$ is independent of $y$, and Eq. (lb) gives

$$
\mathrm{v}_{1 / 2}=y \partial^{2} \mathrm{p}_{1 / 2} / \partial x^{2}+\mathrm{H}(\mathrm{x}, \zeta, t)
$$

The unit normal to the pipe is

$$
\underset{m}{\hat{n}}=-x \hat{x} \pm\left(1-x^{2}\right)^{1 / 2} \hat{y}, \quad \text { at } \quad y= \pm\left(1-x^{2}\right)^{1 / 2} \text {. }
$$

The boundary condition on the velocity is $\underset{m}{v} \cdot \hat{n}=0$ at the pipe, and applying this to Eqs. $(37,38)$ gives two equations. If these two equations are added to and subtracted from each other, the results are 


$$
\left(1-x^{2}\right) \partial^{2} p_{1} / 2 / \partial x^{2}-x \partial p_{1} / 2 / \partial x+x \partial \phi_{0} / \partial \zeta=0
$$

and $H=0$, respectively. The boundary condition [Eq. (9)] holds where

$$
\text { - } E_{\theta}=-\dot{\mathrm{f}} \sin ^{2} \theta+\sin \theta \partial \phi_{0}(\cos \theta, \zeta) / \partial x \text {, at } r=1 \text {, }
$$

since $\mathrm{E}_{\mathrm{yo}}=0$. Applying Eq. (9) to Eq. (36) gives two equations. If these equations are added to and subtracted from each other, the results are.

$$
\left(1-x^{2}\right) \partial^{2} \phi_{0} / \partial x^{2}-x \partial \phi_{0} / \partial x+x \partial p_{1 / 2} / \partial \zeta=0
$$

and $j_{\mathrm{y}_{1}}=-2 \dot{\mathrm{f}} \mathrm{x}$, respectively.

Equations $(39,40)$ governing the slow decay of the disturbance variables $\phi_{0}$ and $\mathrm{P}_{1 / 2}$ in the pipe are identical to those treated by Walker and Ludford ${ }^{8}$ for the slow decay of disturbances in pipes upstream and downstream of an expansion or contraction in a uniform, steady magnetic field, and also to those treated by Holroyd and Walker 2 for the slow decay of disturbances in a pipe upstream and downstream of a region of nonuniform magnetic field. The solutions are expressed in terms of eigenfunction expansions,

$$
\begin{aligned}
& \phi_{0}=\sum_{i=1}^{\infty} a_{i} \Phi_{i}(x) \exp \left(\kappa_{i} \zeta\right), \\
& p_{1 / 2}=\sum_{i=1}^{\infty} a_{i} P_{i}(x) \exp \left(\kappa_{i} \zeta\right) .
\end{aligned}
$$

The first 30 eigenvalues, $k_{i}$, and the methods of obtaining the coupled eigenfunctions, $\Phi_{i}(x)$ and $P_{i}(x)$, from Mathieu functions, or through numerical analysis, are presented by Holroyd and Walker. ${ }^{12}$ Matching the solutions in this long region and in region III shows that $\phi_{0}$ at 
$\zeta=0$ equals $\phi$ in region III, which is known. This boundary condition determines the coefficients $a_{i}$ in Eq. (41). As $\zeta \rightarrow-\infty$, both $\phi_{0}$ and Pl/2 approach zero, and Eqs. $(36,37,38)$ approach the solution for an. infinitely long pipe. Inside regions $I$, II, and III, the $O\left(\varepsilon^{1 / 2}\right)$ current follows the characteristic surfaces (see Fig. 13).

The analysis indicates that end effects disturb the infinite-pipe flow over a long, $O\left(\varepsilon^{-1 / 2}\right)$ length. However, the eigenvalues are very large (e.g., $\kappa_{1}=10.6, \kappa_{2}=34.7$, and $\left.\kappa_{3}=72.5\right)$. Therefore, the exponentials in Eq. (41) go to zero very rapidly as $-\zeta$ increases. Indeed, more severe disturbances, treated by Holroyd and Walker ${ }^{12}$ have virtually vanished at $\zeta=-0.2$ or $z=-0.2 \varepsilon^{-1 / 2}$. With $\varepsilon=0.011$, the disturbance is confined to $z>-2$; i.e., the disturbance decays in a distance equal to two radii or one diameter, so that in reality, the flow deviates from the flow for the infinitely long pipe only within one diameter of the ends.

The pressure, minus the constant pressure $p_{o}$, is $O\left(\varepsilon^{1 / 2}\right)$ in the neighborhood of the hemispherical cap, and $p-p_{o}$ is $O(\varepsilon)$ in the infinitely long pipe, so that the former is much larger than the latter, namely $O\left(\varepsilon^{-1 / 2}\right)$ times larger. However, the stress calculations presented in Sect. 5 are based on the values of $p-p_{0}$ for the coaxial case, rather than for the noncoaxial case considered here, because $\mathrm{p}-\mathrm{p}_{\mathrm{o}}$ for the coaxial case is 43.8 times that for the noncoaxial case for an infinitely long pipe. Since $\varepsilon^{-1 / 2} \approx 10$, then $p-p_{0}$ for the coaxial case is still larger than the $\mathrm{p}-\mathrm{p}_{\mathrm{o}}$ near the hemispherical end for the noncoaxial case; so the etresees presented in sect. 5 are st111 the 1argest. In addition, the hemispherical cap and adjacent onediameter length of pipe, where the flow deviates from that in an infinitely long pipe, are considerably stronger than a long section of pipe. 
THIS PAGE

WAS INTENTIONALLY

\section{LEFT BLANK}




\section{CONCLUSIONS}

Sections 3 and 4 treat the flows and forces due to time-dependent axial and transverse magnetic fields separately. From Fig. 1, it is clear that most cylinders in the reactor are at some angle to the timedependent poloidal field, so that they experience time-dependent axial and transverse magnetic fields simultaneously. If we treat an infinitely long pipe with $\underset{m}{\mathrm{~B}}=\mathrm{B}_{x}(t) \underset{m}{\hat{x}}+\mathrm{B}_{y} \underset{\mathrm{y}}{\hat{y}}+\mathrm{B}_{z}(t) \underset{m}{\hat{z}}$, we find that the governing equations [Eq. (1)] and boundary conditions [Eqs. $(2,9)]$ separate into two independent boundary value problems. One problem governs $w, E_{x}, E_{y}$, $j_{x}$, and $j_{y}$, is driven by $B_{z}(t)$ alone, and is identical to the problem of which the solution is presented in sect. 3. The other problem governs $u, v, E_{z}$, and $j_{z}$, is driven by $B_{x}(t)$ alone, and is identical to the problem of which the solution is presented in Sect. 4; therefore, solutions can be superposed. The only coupling occurs because $j_{y}$ in the noncoaxial case (Sect. 3) interacts with $\mathrm{B}_{x}(t)$ in the coaxial case (Sect. 4) to produce an axial pressure gradient, which does not appear in the separate solutions. However, this pressure gradient and that given by $\mathrm{Eq}$. (10) for the noncoaxial case are $O(\varepsilon)$, and the pressure gradient given by Eq. (16) for the coaxial case is $O(1)$ and neglects $O(\varepsilon)$ terms. Therefore, for the combined axial and transverse field problem, the pressure is given by Eq. (16), neglecting $O(\varepsilon)$ terms. The largest stresses presented in sect. 5 are computed from the pressure differences given by Eq. (16) and are therefore valid for the combined field case with the same transverse magnetic field.

The numerical examples in this paper for the ORNL/Westinghouse Tokamak Blanket $S_{t u d y}{ }^{3}$ result in stresses and pressures that tend to be negligible. This is a consequence of the fact that the minimum dimension of the module is small. It is indicated further that if the minimum dimension is approximately equal to the blanket thickness, then stresses are at a level that may represent infeasibility. 
THIS PAGE

WAS INTENTIONALLY

LEFT BLANK 


\section{ACKNOWLEDGMENT}

This research was supported partly by the National Science Foundation under Grant ENG-7423778 and partly by the Office of Fusion Energy (ETM), U.S. Department of Energy under contract W-7405-eng-26 with the Union Carbide Corporation.

\section{REFERENCES}

1. W. C. Brenner, Mechanical Response of Fluid Containing Blanket Modules to Pulsating Magnetic Fields, WFPS-TME-109, Westinghouse Electric Corporation (December 1978).

2. W. M. Stacy et al., Tokamak Experimental Power Reactor Conceptual Design, ANL/CTR-76-3, Argonne National Laboratory (August 1976).

3. J. S. Karbowski, Tokamak Blanket Design Program - Final Report, WFPS-TME-102, Westinghouse Electric Corporation (October 1978).

4. R. J. Onega, Major Plasma Dismuptions in TNS, ORNL/TM-6616, Oak Ridge National Laboratory (February 1979).

5. P. H. Roberts, An Introduction to Magnetohydrodynamics, American Elsevier, New York, 1967.

6. J. C. R. Hunt and R. J. Holroyd, Applications of Laboratory and Theoretical MHD Duct Flow Studies in Fusion. Reactor Technology, CLM-R169, Culham Laboratory (May 1977).

7. P. H. Roberts, Singularities of Hartmann Layers, Proc. R. Soc. London, Ser. A 300, 94-107 (1967).

8. J. S. Walker and S. S. S. Ludford, Int. J. Eng. Sc1. 13, 261-269 (1975) .

9. J. C. R. Hunt and J. A. Shercliff, Annual Reviews of Fluid Mechanics, Annual Reviews, Inc., California, 1971.

10. D. Steiner, ORNL TNS Program - Summary of FY 1978 Activities, to be published as ORNL/TM-6720, in press.

11. F. B. Seeley and J. 0. Smith, Adrancod Mechanies of Muteroiazs, 2nd ed., John Wiley \& Sons, Inc., New York, 1955.

12. 'R. J. Holroyd and J. S. Walker, J. Fluid Mech. 84, 471-495 (1978). 


\section{THIS PAGE}

\section{WAS INTENTIONALLY \\ LEFT BLANK}


ORNL/TM-6907

Dist. Category UC-20 d

INTERNAL DISTRIBUTION

1. W. R. Becraft

2. L. A. Berry

3. E. E. Bloom

4. T. G. Brown

5. J. D. Callen

6. D. D. Cannon

7. J. L. Dunlap

8. W. A. Houlberg

9. T. J. Huxford

10. M. S. Lube1I

11. J. W. Lue

12. 0. B. Morgan

13. $\mathrm{Y}-\mathrm{K}$. M. Peng

14. R. L. Reid

15. M. W. Rosenthal

16. C. Sardella
17. J. L. Scott

18. T. E. Shannon

19. J. Sheffield

20. D. Steiner

21. J. S. Watson

22-32. W. M. We11s

33. G. W. Wiseman

34-35. Central Research Library

36-37. Fuston Energy Division Library

38. Fusion Energy Division Communications Center.

39-40. Laboratory Records Department

41. Laboratory Records, ORNL-RC

42. ORNL Patent Office

43. Document Reference Section

\section{EXTERNAL DISTRIBUTION}

44. D. J. Anthony, General E1ectric Co., Bldg. 23, Rm. 290, 1 River Rd., Schenectady, NY 12345

45. J. F. Baublitz, Office of Fusion Energy, Department of Energy, Washington, DC 20545

46. D. S. Beard, Office of Fusion Energy, Depaitment of Energy, Washington, DC 20545

47. S. L. Bogart, Science Applications, Inc., 8400 Westpark Drive, McLean, VA 22102

48. R. Botwin, Grumman Aerospace Corp., Bethpage, NY 11714

49. J. H'. C'larke, Office of Fusion Energy, Department of Energy, Washington, DC 20545

50. F. E. Coffman, Office of Fusion Energy, Department of Energy, Washington, DC 20545

51. D. Cohn, Massachusetts Institute of Technology, Cambridge, MA 02139

52. Library, Culham Laboratory, Abingdon, Oxon, OX14 3DB, United Kingdom

53. H. W. Deckman, Advanced Energy Systems Laboratory, Government Research Laboratories, Exxon Research and Engineering Co., P:0. Box 8, Linden, NJ 07036

54. C. A. Flanagan, Westinghouse Electric Corp., Fusion Power Systems, P.0. Box 10864, Pittsburgh, PA 15236

55. H. K. Forsen, Exxon Nuclear Co., Inc., 777 106th Ave., Bellevue, WA 98009 
56. H. P. Furth, Princeton Plasma Physics Laboratory, Princeton University, P.0. Box 451, Princeton, NJ 08540

57. R. W. Gould, Mail Stop 116-81, California Institute of Technology, Pasadena, CA 91125

58. R. Hancox, Culham Laboratory, Abingdon, Oxon, $0 \times 14$ 3DB, United Kingdom

59. C. R. Head, Office of Fusion Energy, Department of Energy, Washington, DC 20545

60. R. L. Hirsch, Fxxon Research and Engineering Co., P.O. Box 101, F1orham Park, NJ 07932

61. M. A. Hoffman, Lawrence Livermore Laboratory, P.0. Box 808, Livermore, CA 94550

62. Anthony Hsu, Office of Fusion Energy, Department of Energy, Washington, DC 20545

63. D. L. Jassby, Eriliceton Plasma Phyjics Laboratory, Prinnaton üniversicy, P.0. 4J1, P\& Liletuil, NJ 00540

64. V. A. Maroni, Argonne National Laboratory, 9700 South Cass Ave., Argonne, IL 60439

65. D. M. Meade, Princeton Plasma Physics Laboratory, Princeton Untversity, P.0. Box 451, Princeton, NJ 08540

66. P. B. Mohr, Lawrence Livermore Laboratory, P. . . Box 808, Livermore, CA 94550

67. M. R. Murphy, Office of Fusion Energy, Department of Energy, Washington, DC 20545

68. J. M. Rawls, General Atomic Co., P.o. Box 81608, San Diego, CA 92138

69. P. Reardon, Princeton Plasma Physics Laboratory, Princeton University, P.n. Bnx 451, Princetenn, N.J 08540

70. T. Reuther, Office of Fusion Energy, Department of Energy, Washington, DC 20545

71. M. Roberts, Uffice of Fusion E'nergy, Department of Energy, Washington, DC 20545

72. P. H. Sager, Jr., General Atomic Co., P.0. Box 81608, San Diego, CA 92138

73. G. Schilling, Princeton Plasma Physics Laboratory, Princeton University, P.0. Box 451, Prinçetọ, NJ 08540

74. W. M. Stacey, Jr., School of Nuclear Engineering, Georgia Institute of l'echnology, Atlanta, is 30332

75. F. Thomas, Grumman Aerospace Corp., Bethpage, NY 11714

76. T. C. Varljen, Westinghouse Electric Corp., Fusion Power Systems, P.0. Box 10864, Pittsburgh, PA 15236

77. S. S. Waddle, Department of Energy, Oak Ridge Operations, P.o. Box E, Oak R1dge, TN 37830

78-88. J. S. Walker, University of Illinois, Urbana, IL 61801

89. J. Willis, Office of Fusion Energy, Department of Energy, Washington, DC 20545

90. W. Wilkes, Mound Laboratories, Miamisburg, OH 45432

91. E. Ziurys, Office of Fusion Energy, Department of Energy, Washington, DC 20545

92. K. Zwilsky, Office of Fusion Energy, Department of Energy, Washington, DC 20545 
93. Office of Assistant Manager, Energy Research and Development, Department of Energy, Oak Ridge Operations, P.O. Box E, Oak Ridge, TN 37830

94-244. Given distribution as shown in TID-4500, Magnetic Fusion Energy (Distribution Category UC-20 d, Fusion Systems) 